\title{
Intensional Transitive Verbs and Abstract Clausal Complementation*
}

\author{
Richard Larson, Marcel den Dikken and Peter Ludlow \\ Stony Brook University, City University of New York, Northwestern University
}

Intensionality phenomena are known to show a strong correlation with syntax. In simple transitive constructions intensionality effects are standardly absent. Substitution of co-referring object NPs preserves truth $(1 a, b)^{1}$; furthermore, the presence of a nonreferring or nondenoting object yields a false sentence (1c):
a. Max met [DP Boris Karloff].
b. Max met [DP Bill Pratt].
c. Max met [DP a unicorn].

By contrast, intensionality manifests itself with all clausal complement constructions. Substitution of co-referring terms in the complement needn't preserve truth $(2 \mathrm{a}, \mathrm{b})$; and the presence of a nonreferring or nondenoting term needn't induce falsity $(2 c):^{2}$
a. Max imagined [CP that [DP Boris Karloff] was approaching]
b. Max imagined [CP that [DP Bill Pratt] was approaching]
c. Max imagined [CP that [DP a unicorn] was approaching]

Although pervasive, the correlation between syntax and semantics found in (1) - (2) seems to be violated by a small class of verbs showing the surface grammar of transitives but the semantic behavior of clause-taking predicates. So-called intensional transitive verbs like want, imagine, expect, need, look for appear to take a direct object, but substitution of this term may not preserve truth, and the presence of an empty term need not yield a false sentence:

(3) a. Max imagined/wanted/needed/looked-for [DP Boris Karloff].

b. Max imagined/wanted/needed/looked-for [DP Bill Pratt].

c. Max imagined/wanted/needed/ looked-for [DP a unicorn].

In view of their special behavior, the analysis of intensional transitives has been controversial.

\footnotetext{
* We are grateful for comments to Robert Fiengo, Kai von Fintel, Janet Fodor, Jerry Fodor, James Huang, Richard Kayne, Ernie Lepore, Jim McCloskey, Friederike Moltmann, Ian Roberts, and to audiences at CUNY, University of Delaware, UC-Irvine, MIT, Novi Sad, Potsdam, Rutgers University and The University of Venice.

1'Boris Karloff' was the stage name taken by Mr. William Henry Pratt.

${ }^{2}$ For interesting recent discussion of substitutivity in intensional and extensional contexts, see Forbes (1996, 1997a) and Saul (1997). In this paper we will assume that failure of substitutivity and ability to take a non-denoting object without inducing falsity are correlated properties; this assumption is challenged, however, in Bonomi (1995) and Forbes (1997b), and as we will see in section 6, the correlation may have to be relaxed in certain cases. In view of the possibility of such cases, we might define an intensional environment as one that both (i) blocks substitution and (ii) allows non-referring expressions.
} 
In this paper, we defend a view of intensional transitives which is intuitive and quite familiar, but one which has also been widely discounted. Specifically, we defend the proposal deriving from Quine (1960) and Montague (1960) that despite surface appearances, constructions like (3a-c) are not transitives at all, but rather clausal complement constructions containing concealed material. ${ }^{3}$

a. Max wanted/imagined/needed/ looked-for [DP Boris Karloff].

b. Max wanted/imagined/needed/ looked-for [CP...[DP Boris Karloff]...].

On this proposal, the intensionality effects found with the "objects" of verbs like want and imagine are expected and indeed follow from their underlying syntax.

In part 1, we present some background for the clausal analysis of intensional transitives, including familiar semantic evidence, and in part 2, we provide a brief account of the syntax of non-finite complement constructions within the general framework of Chomsky (1995). In part 3 , we offer our analysis of concealed for-to complements. These include hope-for and want-type verbs, whose complements we analyze as containing a covert verb HAVE, and they include lookfor and seek-type verbs, whose complements we analyze as containing a covert verb FIND. A key feature in our analysis is its appeal to restructuring along lines discussed by Burzio (1986) and Baker (1988) for certain forms of causatives. In part 4, we extend the account to verbs like imagine and expect, which we analyze as selecting a concealed ECM complement. We close in part 5, with a survey some extensions of our analysis and some remaining challenges to it.

\section{Background: Intensional Transitives as Clause-taking}

The view that constructions like (5) and (6) are only apparently transitive has been urged by McCawley (1974), Karttunen (1976), and Ross (1976). A variety of evidence is advanced in support of this view.

\subsection{Selectional Restrictions}

Transitive predicates showing intensionality effects also typically allow overt clausal complementation, whereas nonintensional transitives never do. For example, the intensional transitive imagine permits a full clause to follow it, whereas the nonintensional transitive meet does not. This suggests that the ability of verbs like imagine to induce intensionality effects in an "object" nominal is somehow tied to their clausal selection properties.

In addition, Ross (1976) points out that specific selectional properties of certain intensional transitives suggest a hidden complement. Thus he notes that selection by "transitive" want (and similarly need, expect, require, demand, would-like, seek, hope-for, beg-for, plead-for,

\footnotetext{
${ }^{3}$ Quine (1960) doesn't actually propose that English has a clausal complements in these cases, but rather that we can "regiment" English to suit our needs. Accordingly, Quine does not advance an empirical thesis about the structure of English. Montague (1960) considers the idea as a substantive thesis about English, and attributes the idea to the medieval logicial Buridan. If Buridan (1966) is any indication however, Buridan was merely reporting (and rejecting) a thesis that was already familiar to the medievals. Parenthetically, the specific thesis was that $I$ owe Jean a horse, might be analysed as I owe that I give Jean a horse, thus allowing the reading in which no particular horse is owed Jean.
} 
etc.) tracks that of have very closely. Ross offers the following paradigms:
a. I want
a cold
a sister
freedom
a driveway
\#sentencehood
b. I have
a cold
a sister
freedom
a driveway
\#sentencehood

If apparent complements to want (and similarly need, expect, require, demand, would-like, seek, hope-for, beg-for, plead-for, etc.) are actually complements of an inaudible HAVE in a concealed clause, then these parallelisms are directly explained (6). ${ }^{4}$

$$
\text { I want TO HAVE }\left\{\begin{array}{l}
\text { a cold } \\
\text { a sister } \\
\text { freedom } \\
\text { a driveway } \\
\text { \#sentencehood }
\end{array}\right.
$$

\subsection{Binding Effects}

Ross (1976) attributes to Perlmutter the observation that certain abstract nouns such as help, cooperation, sympathy, etc. show disjointness effects following have. When a possessive pronoun modifying $\mathrm{N}$ is coreferential with the subject the sentence is odd (7):
a. I had $\left\{\begin{array}{l}* \text { my cooperation. } \\ \text { your/his/their/Ed's cooperation. }\end{array}\right.$
b. You have $\left\{\begin{array}{c}\text { *your sympathy. } \\ \text { my/his/their/Ed' }\end{array}\right.$
c. $\mathrm{Ed}_{\mathrm{i}} \mathrm{had}$

$$
\left\{\begin{array}{c}
* \text { his } \mathrm{s}_{\mathrm{i}} \text { help. } \\
\text { hisj/my/her/their help. }
\end{array}\right.
$$

Ross notes this same disjointness effect occurs with want (and similarly desire, need, expect, require, demand, would-like, seek, hope-for, beg-for, plead-for, etc.) substituted for have in (8), but that the effect is absent with other transitives (9):
a. I want $\left\{\begin{array}{l}* \text { my cooperation. } \\ \text { your/his/their/Ed's cooperation. }\end{array}\right.$
b. You want *your sympathy.
c. Ed $\mathrm{d}_{\mathrm{i}}$ wants ${ }^{*}$ hisis help.
his $_{\mathrm{j}} / \mathrm{my} /$ her/their help.

\footnotetext{
${ }^{4}$ This parallel also extends to all so-called "light verb" uses of have as well. Thus Max had a bath is equivalent to Max bathed; similarly Max wanted a bath is equivalent to Max wanted to bathe:

(i) a. I want a bath/a nap/a drink/a smoke...

b. I had a bath/a nap/a drink/a smoke...
} 
(9)

I $\left\{\begin{array}{l}\text { mentioned } \\ \text { boasted about } \\ \text { described } \\ \text { played up } \\ \text { regretted }\end{array}\right\}$ my/your/his/their/Ed's $\left\{\begin{array}{l}\text { cooperation } \\ \text { help } \\ \text { sympathy }\end{array}\right.$

Ross takes these facts to argue directly for have in the complement of "transitive" want: ${ }^{5}$

Ed $_{\mathrm{i}}$ wants $\left[\mathrm{PRO}_{\mathrm{i}}\right.$ TO HAVE $*$ his $_{\mathrm{i}}$ help]

\subsection{Adverbial Modification}

McCawley (1974), Karttunen (1976), and Ross (1976) observe that intensional transitives often show adverbial ambiguities similar to those arising with clausal complementation. ${ }^{6}$ For example, $(11 \mathrm{a}, \mathrm{b})$ are both ambiguous depending on what the adverb tomorrow is understood as modifying:
a. Max will need to have a bicycle tomorrow.
(ambiguous)
b. Max will need a bicycle tomorrow.
(ambiguous)

In (11a), the adverb can be understood as modifying the matrix verb need or the embedded verb have. On the former (nonpreferred) reading, it is the needing that will be tomorrow (cf. Tomorrow Max will need to have a bicycle). On the latter reading, it is the having that will be

\footnotetext{
${ }^{5}$ The source of obviation in cases like (7) is an interesting question. Although we cannot pursue the point here, we believe the disjointness observed with have in (i) is similar to the well-known effect observed with be in (iia), which Fiengo and May (1993) assimilate to the ill-formedness of (iib).

(i) $\quad * \mathrm{Ed}_{\mathrm{i}}$ has his sympathy.

(ii) a. ${ }^{*} \mathrm{Ed}_{\mathrm{i}}$ is his $\mathrm{i}$ cook.

b. ${ }^{*} \mathrm{Ed}_{\mathrm{i}}$ is the cook for $\mathrm{him}_{\mathrm{i}}$

Plausibly, the disjointness effect in (ii) can be accounted for using a binding theory framed in terms of complete functional complexes (CFCs) (Chomsky (1986)). Assuming a copular analysis of be (Stowell (1981), Couqueax (1982)), the structure of (iia,b) is (iiia,b), respectively, where $E d$ is underlyingly the subject of his cook and the cook for him. Assuming that his/him is a benefactive argument of cook, coindexing Ed and his/him yields a pronoun that is bound within its minimal CFC violating Principle B. This effect is absent with transitives like John fired his cook since John does not originate within the CFC of cook in such cases.

(iii) a. ${ }^{*} \mathrm{Ed}_{\mathrm{i}}$ is $\left[\mathrm{t}_{\mathrm{i}} \mathrm{his}_{\mathrm{i}}\right.$ cook $]$

b. $* \operatorname{Ed}_{\mathrm{i}}$ is $\left[\mathrm{t}_{\mathrm{i}}\right.$ the cook for $\left.\mathrm{him}_{\mathrm{i}}\right]$

It seems to us that this account might be extended to have in (i) under the general Benveniste-Freeze-Kayne analysis, relating have constructions to be+dative. On the BFK approach, the relevant structure for (i) might be approximately as in (iva,b), with be+to spelled out as have:

(iv) a. $\quad$ be $\left[\right.$ his $_{\mathrm{i}}$ sympathy to $\left.\mathrm{Ed}_{\mathrm{i}}\right]$
b. $* \overline{E d}_{i}$ be+to $\left[\right.$ his $_{i}$ sympathy $\left.t_{i}\right]$

Again, assuming that the pronoun is an argument of sympathy (plausible given the near synonymy of (i) with $E d$ sympathizes with him), coindexing Ed and his yields a pronoun bound within its minimal CFC; hence the example is out. This effect is absent with transitives like John mentioned his sympathy since John does not originate within the CFC of sympathy in such cases.

${ }^{6}$ Ross (1976) credits the observation of adverbial ambiguities with want to Masaru Kajita.
} 
tomorrow (cf. Max will need to have a bicycle, and he must have it tomorrow). This ambiguity can be analyzed as directly arising from the two possible attachments for tomorrow:

(12) a. [Max will need [PRO to have a bicycle tomorrow]]

b. [Max will need [PRO to have a bicycle] tomorrow]

If an underlying clausal analysis is provided for (11b), then its ambiguity can be analyzed in a completely parallel way (13):

a. [Max will need [CP PRO HAVE a bicycle tomorrow]]

b. [Max will need [CP PRO HAVE a bicycle] tomorrow]

If we reject this approach, however, we not only need to provide an alternative analysis of the ambiguity in (11b), we must also explain why ambiguity fails to arise with extensional transitives that do not select clauses - why, for example, no comparable ambiguity arises in (14):

$$
\text { Max will ride/repair a bicycle tomorrow. } \quad \text { (unambiguous) }
$$

In a similar vein, McCawley (1974) observes that intensional transitives like want allow for the possibility of two non-agreeing time adverbs (15a), whereas garden-variety transitives like paint do not (15b). Again, if an underlying clausal analysis is provided for (15a), then the coherence of this example is directly comparable to the coherence of (16):

(15) a. A week ago Bill wanted your car yesterday

b. \#A week ago Bill painted your car yesterday

(16) [A week ago Bill wanted [CP PRO to have your car yesterday]].

If we reject the biclausal approach, we require an alternative (and presumably unrelated) analysis of why (15a) involves no "temporal clash".

\subsection{Ellipsis}

Evidence for clausal complementation with "transitive" want is provided by the understanding of elliptical examples like (17): ${ }^{8}$

a. A: Do you want another sausage?

B: I can't [vp Ø ]. I'm on a diet.

(cf. A: Do you want to have another sausage?

B: I can't have another sausage. I'm on a diet.)

b. A: Do you want a beer?

\footnotetext{
${ }^{7}$ To our knowledge, this correlation of facts has simply not been addressed in non-clausal accounts of intensional transitive complements. See for example, Montague (1974), which analyzes the complements of intensional transitives as denoting properties of properties; see also the latest work in this framework, e.g., Zimmermann (1993), Moltmann (1997).

${ }^{8} \mathrm{We}$ are grateful to Jerry Fodor and Ernie Lepore for extensive discussion of these and related examples.
} 
B: I shouldn't [vp Ø], but I will [vp Ø ] just this one time.

(cf. A: Do you want to have a beer?

B: I shouldn't have a beer, but I will have a beer just this one time.)

What is reconstructed in the VP ellipsis site in these cases appears to be a VP involving have.

Similarly, consider the sequence of examples in (18), pointed out to us by David Pesetsky (p.c.). Pesetsky observes that (18a), involving comparative ellipsis, has interpretations equivalent to either (19a) or (19b). Perhaps surprisingly, however, (18b) is similarly ambiguous. Thus (18b) may be understood as asserting that Jonathan wants (to have) more toys than Benjamin wants (to have); but it also may be understood as asserting that Jonathan wants more toys than Benjamin has, however many that might be.

(18) a. Jonathan wants to have more toys than Benjamin.

b. Jonathan wants more toys than Benjamin.

(19) a. Jonathan wants to have more toys than Benjamin wants to have.

b. Jonathan wants to have more toys than Benjamin has.

The analysis of this ambiguity is straightforward if "transitive" want involves a clausal complement: the ambiguity of (18b) simply assimilates to the ambiguity of (18a). By contrast if no such complement is present, the analysis of comparative ellipsis reconstruction becomes considerably more complicated. ${ }^{\text {' }}$

\subsection{Propositional Anaphora}

McCawley (1974) observes that nominal objects of intensional transitives license propositional anaphora. Thus he points out that the it appearing after allow in (20a) cannot be anaphoric to $a$ horse in the preceding clause since it does not otherwise agree with the latter in number or gender (cf. $(20 b, c))$ :

\footnotetext{
${ }^{9}$ McCawley makes an interesting point about intensional transitives in connection with the comparative ellipsis examples in (i). Supposing Sam has $\$ 100$ and the speaker has $\$ 90$, McCawley suggests that the want expressed by (i) could be satisfied in either of two ways: by giving the speaker more than $\$ 100$, or by giving the speaker more than $\$ 10$ :
}

(i) I want more money than Sam has.

McCawley ties what he detects as an ambiguity in (i) to the presence of either of two (concealed) Vs in the complement of want: GET or HAVE. Thus the want that would be satisfied by getting more than $\$ 100$ correlates with the structure in (iia); and the want that would be satisfied by getting more than $\$ 10$ or more correlates with the structure in (iib):

(ii) a. I want to get more money than Sam has

b. I want to have more money than Sam has

It is unclear whether this is an ambiguity involving GET vs. $H A V E$, or an ambiguity involving $H A V E$ alone. Supposing I have $\$ 90$, (iii) seems to have a reading under which my want would be satisfied by getting $\$ 10$ from the listener, and a reading under which my want would only be satisfied by getting a full $\$ 100$ from the listener (the latter is brought out by adding from you to the complement:

(iii) I need to have $\$ 100$ (from you)

If have already contains the observed ambiguity/polysemy, it seems reasonable to attribute the same meaning variation to $H A V E$. 
a. Joe wants a horse, but his mother won't allow it.

b. Joe wants some horses, but his mother won't allow it/*them.

c. Joe wants a wife, but his mother won't allow it/*her.

On the other hand, if what follows want is a clausal complement, then the anaphoric relations in (20) are analogous to those in (21), where it simply refers back to the preceding clause:

(21) Joe wants [PRO to have a horse], but his mother won't allow it.

(cf. Joe wants to have a horse, but his mother won't allow Joe to have a horse.)

\section{The Syntax of Non-finite Clausal Complements}

The concealed clause analysis clearly has empirical motivation, and also has the virtue of reducing unexpected properties of apparent transitive constructions with want, need, imagine, etc. to the expected properties of clausal complement constructions with the same verbs. At the same time, however, the analysis raises a large number of syntactic issues. We are immediately faced with the question of what form concealed complement clauses take, and what principles license their parts. Furthermore, we have to face some divergences in the behavior of intensional transitives and their overt clausal counterparts. For example, if "objects" of intensional transitives arise in a complement clause, then why can they be passivized when their overt clausal counterparts cannot?

a. Crackers are preferred/wanted/desired/hoped for.

b. *John is preferred/wanted/desired/hoped for to leave.

To address these issues, we begin by examining the analysis of overt nonfinite complements, with particular attention to the issue of Case assignment.

\subsection{ECM Complements (Lasnik \& Saito 1991, Lasnik 1993)}

Lasnik \& Saito (1991) and Lasnik (1993) propose an interesting account of ECM constructions like (23a) that captures some aspects of the "raising to object" analysis defended by Postal (1970). The authors propose that (23a) involves a covert raising operation in which the subject him of the embedded clause $\left(\operatorname{Agr}_{\mathrm{s}} \mathrm{P}\right)$ moves to $\mathrm{Spec} \mathrm{Agr}_{\mathrm{o}}$ where accusative Case is checked (23b). Thus although the embedded subject never becomes a thematic object of believe, it does become an object with respect to Case:

(23) a. Max [vp believes [AgrsP him to be patient]].

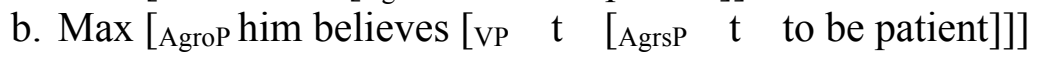

The Lasnik and Saito analysis has a number of attractive features. For example, it allows the ability of an ECM subject anaphor to be bound by a higher subject to be explained under something like the early (and conceptually simple) clausemate condition. At LF, the anaphor and antecedent are in a highly local relation: they are constituents of the same clause (24a). The analysis also clarifies certain issues left open in earlier accounts. For example, consider the 
question of why there are no three-argument ECM verbs: no verbs parallel to persuade, but which take an ECM clause rather than a control complement (24b.i).

a. Max [AgroP himself believes [vP $\mathrm{t}$ [AgrsP $\mathrm{t}$ to be patient]]

b. i. *Max VERB Seymour [Agrsp him to be patient]

ii. Max [AgroP Seymour VERB t [AgrsP him to be patient]]

At an earlier stage of the theory, two hypotheses were available: (24b.i) is out because him fails to be adjacent to the Case assigner $V E R B$; alternatively, $(24 \mathrm{~b} . \mathrm{i})$ is out because $V E R B$ would only have one Accusative Case to assign, and hence one of Seymour or him must go Caseless. Under the Lasnik and Saito approach, we can now resolve the question in favor of the latter: adjacency becomes irrelevant; (24b.i) is out because $\operatorname{Arg}_{o}$ can check the Case of at most one of Seymour or him.

\subsection{For-to Complements}

We adopt the Lasnik and Saito analysis and propose to extend it to infinitival for-complements, which have also standardly been assumed to involve exceptional Case-marking. In Chomsky (1981), for example, it is proposed that (25a) involves Case-marking of the subject him across a sentence boundary (here identified as $\operatorname{Agr}_{\mathrm{s}} \mathrm{P}$ ) by the prepositional complementizer for. We suggest that such cases be analogized to the believe-type, with the modification that with these verbs, the complementizer for raises and incorporates into the matrix V (25b). This V-P complex then checks Accusative Case on the embedded subject $(25 \mathrm{c}) .{ }^{10}$
a. Max [vp prefers [CP for [AgrsP him to be patient]]]
b. Max [vp prefers-for [ $\mathrm{CP} t$ [AgrsP him to be patient]]]
c. Max [AgroP him prefers-for [VP $\quad t \quad[\mathrm{CP} t \quad[$ AgrsP $t \quad$ to be patient]]]

With examples like (26a), where no overt prepositional complementizer appears, we make the standard assumption that the structure contains an unpronounced counterpart to for (FOR) $(26 b):^{11}$

(26) a. Max wants him to be patient.

b. Max [vp wants [CP FOR [AgrsP him to be patient]]]

c. Max [AgroP him wants-FOR [vP $\quad \mathrm{t} \quad[\mathrm{CP} t \quad[$ AgrsP $t$ to be patient]]]

Inaudible FOR is assumed to bear an Accusative Case feature and to incorporate and check Case in concert with the verb, exactly like its overt counterpart (26c). ${ }^{12}$

This analysis inherits one attractive feature of the ECM account. Thus, the ability of a

\footnotetext{
${ }^{10}$ For recent discussion of infinitives and Case-assignment, see Boskovic (1995,1996), Martin (1992), Ormazabal (1995), Snyder and Rothstein (1992), and Watanabe (1993).

${ }^{11}$ An alternative is to assume a deletion rule that elides for at PF (under somewhat obscure circumstances).

${ }^{12}$ This analysis owes an evident debt to proposals by Kayne (1983), but essentially inverts the latter's account. Rather than analogizing ECM cases with believe to the want-class by appealing to an inaudible prepositional complementizer $\Phi$, we analogize want to the believe-class, appealing to a form of derived transitivity in the V-P composite.
} 
subject anaphor to be bound by a higher subject is explained in a parallel way (27a): the anaphor becomes a constituent of the higher clause containing its antecedent. ${ }^{13}$ As we will see later, it is somewhat less clear that this account rules out three-argument verbs that take an infinitive with an overt subject rather than $P R O$ (27b.i).

a. Max [Agrop himself prefers-for [VP $\mathrm{t} \quad[\mathrm{CP} t \quad$ [AgrsP $t$ to be patient]]]

b. i. Max VERB Seymour [CP for [Agrs him to be patient]] ii. Max [Agrop Seymour VERB- for $\mathrm{t} \quad[\mathrm{CP} \mathrm{t}$ [AgrsP him to be patient]]

Even if VERB + for/FOR can check the Case of at most one DP, it is still conceivable that the verb could possess its own independent ACC feature, allowing both Seymour and him to have their Cases checked. ${ }^{14,15}$

Evidence for raising can also be derived from recent proposals about Antecedent Contained Deletion phenomena, of which (28a) is an example. Such examples apparently require movement of DP out of the main VP for proper resolution of the elliptical material. ${ }^{16}$ In May ${ }^{13}$ The for-incorporation analysis with want -type verbs is virtually forced under Reinhart and Reuland (1993), which
claims that reflexivization applies to syntactic predicates. A syntactic predicate is formed from a head H, its
syntactic arguments and its external argument; syntactic arguments of H are those elements to which it assigns a $\theta$ -
role or Case. If the reflexive is to be a syntactic argument of prefer in John prefers for himself to win, and if for is
assumed to be the source of Case-assignment, then for must incorporate with prefer and the two must assign Case.
${ }^{14}$ The possibility that both incorporating and incorporated elements contribute Case-features seems to be
independently attested in the case of verb incorporation, as discussed by Baker (1988). We also note that the
incorporations proposed here meet Baker's Case Frame Preservation Principle, which requires that complex heads of
category A in a given language can have at most the maximal Case assigning properties permitted to a
morphologically simple item of category A. See Cho (1997) for arguments that a form of Case-checking analogous
to (27b) explains multiple Accusative marking, as found in Korean "inalienable possession constructions". For
further discussion, see also section 3.2 .3 .
${ }^{15}$ Lasnik and Saito (1991) reject a raising to Agr analysis of want on the basis of a number of arguments, all
involving very subtle data judgments. For example, they note the contrast in (i), due to Bach (1977), where him
and Bob are to be understood as coreferent, and where the adverbial even-clause is to be understood as modifying
the matrix verb. The suggestion is that the reduced acceptability in (ib) reflects a Condition C effect, the product of
raising him to the matrix clause (where it c-commands Bob):

(i) a. ?Joan wants him ${ }_{i}$ to be successful even more fervently than Bob ${ }_{i}$ 's mother does.

b.?*Joan believes him $_{i}$ to be successful even more fervently than Bob ${ }_{i}$ 's mother does.

These judgments are delicate, but even if they are accepted, their interpretation as reflecting Condition $\mathrm{C}$ appears dubious. First, the level of unacceptability in (ib) is surely below that of a standard Condition C violation. Second, the claim that the difference in (ia,b) reflects a matrix versus embedded position for him is directly contradicted by (ii), which should be compared to (ia):

(ii) (?) Joan wants him ${ }_{i}$ even more fervently than Bob ${ }_{i}$ 's girlfriend does.

Coreference in (ii) appears to us to be at least as accessible as in (ia), but note here that there can be no question of him being in the matrix clause at the relevant point (LF). We conclude that whatever may be the source of the contrast in (i), it does not bear on raising to $\operatorname{Agr}_{0}$.

${ }^{16}$ The elided material can be regarded as missing in initial structure and reconstructed at LF, or as present in initial structure and elided at PF. On the first approach, the LF in (28b) is subject to some form of copying operation, yielding the result in (i). On the second approach, the initial form of (28a) is as in (iia), with the boldfaced material deleted at PF. Movement as in (iib) is then necessary to create an appropriate deletion trigger, i.e., one not contained within the deleted material. This trigger must be checked at LF (after raising):

(i) $\quad[$ DP everyone you [vp like t $]][$ Max [vp likes t $]]$

$$
\text { a. [Max [vP likes [DP everyone you [vP like t ]]]] }
$$


(1985) and Larson and May (1990), this movement is attributed to a rule of Quantifier Raising, which extracts DP and adjoins it to the clause (28b). Citing a variety of arguments, however Lasnik (1993) and Hornstein $(1994,1995)$ argue that it is not QR, but rather raising to $\mathrm{Agr}_{\mathrm{O}}$ that is the relevant movement operation in ACD, moving DP out of VP:
a. Max [vp likes [DP everyone you [vp Ø]]]
b. [DP everyone you [vP Ø]] [Max [vp likes t]]
c. Max [Agrop [DP everyone you [vp Ø]] [vp like t ]]

Assuming the latter proposal, examples like (29a-c) with ECM predicates are predicted to be licit; and as noted in Larson and May (1990), Lasnik (1993), and Hornstein (1994,1995), they are. Under the Hornstein-Lasnik analysis, all involve a structure as in (29d), where ellipsis is licensed by raising the postverbal DP to $\mathrm{Agr}_{\mathrm{o}}$ Spec.
a. ?Max believes [everyone you do [vp Ø]] to be a genius.
b. ?Max expects [everyone you do [vp Ø]] to visit Mary.
c. ?Max finds [everyone you do [vp Ø]] to be qualified.
d. Max [AgroP [DP everyone you [vP Ø]] $\mathrm{V}$ [AgrsP $\mathrm{t}$ to VP]]

Consider now (30a-d) which involve want-type predicates, and which to our ear show no difference in acceptability from (29a-c). Again under the Hornstein-Lasnik analysis these must involve raising to raising to $\mathrm{Agr}_{\mathrm{o}} \mathrm{Spec}$, and under the analysis proposed here, shown schematically in (30d), this is exactly what occurs.
a. ?Max wants [everyone you do [vp Ø]] to be elected.
b. ?Max desires [everyone you do [vp Ø]] to visit Mary.
c. ?Max wishes [everyone you do [vp Ø]] to be recognized.
d. Max [AgroP [DP everyone you [vp Ø]] V-FOR [cP t to VP]]

Hence on the Hornstein-Lasnik account, ACD phenomena support the raising analysis. ${ }^{17},{ }^{18}$

\section{b. [DP everyone you [vp like t ]] [Max [vp likes t ]] \\ LCheck-1}

${ }^{17}$ The presence of an overt complementizer for strongly blocks ACD in the want-class examples (cf. (ia-c) versus $(30 \mathrm{a}-\mathrm{c}))$. Presumably this is due to the fact that, at the relevant level of structure, there will be a Comp-trace violation comparable to what is seen in the overt example (ii):

(i) a. *Max wants very much for [everyone you do [VP Ø]] to be elected.

b. *Max desires for [everyone you do [VP Ø]] to visit Mary.

c. *Max wishes for [everyone you do [VP Ø]] to be recognized.

(ii) *Max wants [CP for [DP everyone you [VP want [CP for t to VP ]]] to VP]

${ }^{18}$ Kennedy (1997) presents interesting counterarguments to the general claim that movement to Agr can replace QR in an account of quantifier scope. So far as we can tell, however, Kennedy's point does not undermine Hornstein and Lasnik's general observaion that ACD seems to be licensed primarily in object positions, and not simply in positions from which quantifiers are able to take scope. 


\subsection{Passive}

An important issue that we are obliged to address, one that will become important later, is the analysis of passive. One of the key reasons for resisting a parallel analysis of ECM and for-to constructions is the well-known asymmetry in (31), which shows that ECM verbs allow passivization of the embedded subject whereas for-to verbs do not. Given the close analogy our analysis draws between (23a) and (25a), we require an explanation of the contrast:

(31) a. He was believed to be patient.

b. *He was preferred (for) to be patient.

Note further that options are sparse. Since the embedded subject is assumed to raise smoothly to the Spec of the matrix $\mathrm{Agr}_{\mathrm{o}}$ in both cases, older ECP-based accounts will not work for us. We must take movement to be licit in both cases. Furthermore, the ill-formedness cannot be explained by claiming that the for-to type verbs don't undergo passive at all. Such verbs can passivize the entire complement clause (e.g., For Bill to win is fervently desired by $A l$ ). If there is to be an explanation of (31a) versus (31b) in our account, it would seem to have to appeal to some property of the moved item itself: the subject of an ECM complement versus the subject of a for-to complement. Something about being the subject of a for-to infinitive must block passive. Our answer to this problem appeals to recent proposals about the Case marking of infinitival control subjects.

\subsection{1. "Light Nominative Case" and PRO}

Chomsky and Lasnik (1993) have argued that standard government-based explanations of the distribution of $P R O$ should be replaced by an account based on Case. In brief, they propose that $P R O$ is licensed by a special Null Case that is checked solely by the Tense (to) occurring in infinitival control complements. Null Case is assumed to be the only Case that PRO can bear. Thus in (32) $P R O$ receives Null Case from to, making it visible for $\theta$-role assignment.

$$
\begin{array}{r}
\text { Max [vP prefers [CP [AgrsP PRO to be patient]]] } \\
\text { (null Case on to checked by PRO) }
\end{array}
$$

On this proposal, (33a) is excluded, not because $P R O$ is in a governed position, but rather because the prepositional complementizer for has an Accusative Case feature that cannot be checked by $P R O .{ }^{19}$ (33b) crashes because believe has an Accusative Case feature that cannot be checked by $P R O$, but also because $P R O$ bears a Null Case feature that cannot be checked by the infinitival to in this structure:
a. *Max [vp prefers [CP for [AgrsP PRO to be patient]]]
(ACC Case can't be checked by $P R O$ )
b. *Max believed [PRO to be patient]
(ACC Case can't be checked by $P R O$; no Null Case to license $P R O$ )

\footnotetext{
${ }^{19}$ An important consequence of this analysis, which will be important to us later, is that constructions like (33a) might be rescuable if for had an alternative way of checking its Case feature.
} 
The assumption that the to's occurring in $(33 \mathrm{a}, \mathrm{b})$ differ in capacity to check Case is justified on the basis of their difference in "tense content". As discussed by Bresnan (1972) and Stowell (1982), infinitival complements of non-ECM verbs involve a clear future irrealis meaning, whereas infinitival complements of ECM verbs are essentially tenseless. On the usual assumption that ability to Case-mark/check a subject correlates with the presence of a genuine tense, the contrast postulated by Chomsky and Lasnik between control and ECM verbs appears reasonable.

Chomsky and Lasnik do not comment in detail on the nature of Null Case. They simply suggest that since Null Case is assigned by $\mathrm{T}$ it is essentially equivalent to Nominative. ${ }^{20}$ Likewise they do not comment on examples like (25a), where the infinitival to bearing Null Case co-occurs with a for bearing ACC:

$$
\operatorname{Max}[\mathrm{vP} \text { prefers [CP for [AgrsP him to be patient]]] }
$$

Logically, it seems that both Case features must be checked by the subject him occurring in the lower clause. But how exactly should this go?

Following Chomsky and Lasnik's lead, let us assume that Null Case is in fact a form of Nominative Case, which is "light" in the following sense:

- Chains headed by the phonologically empty element PRO can be made visible by light NOM Case, ${ }^{21}$

- Chains headed by any phonologically contentful element can bear light NOM Case, but cannot be made visible by it.

These proposals entail that a phonologically contentful argument may bear light NOM Case, but that it must also bear another Case feature for convergence. Thus, assume that the embedded subject ( $\mathrm{him}$ ) in a for-to infinitive like (25a) enters the numeration bearing two formal Case features: light Nominative and Accusative. The former is checked by to in the embedded clause; the latter is checked by for in $\mathrm{Agr}_{\mathrm{o}}$ Spec after incorporation of $\mathrm{C}$ to $\mathrm{V}$ and raising of $\mathrm{V}-\mathrm{C}$ :

${ }^{20}$ Sigurdsson (1991) provides compelling evidence that PRO in Icelandic is Case-marked, and further that Icelandic $P R O$ s that do not bear Quirky Case are assigned Nominative Case in infinitival control complements. Thus he notes that floating quantifiers (allir) and passive participles (kosnir) show Case agreement, and when such elements occur in infinitival control complements not involving Quirky Case, their inflection is invariably Nominative (ia,b):

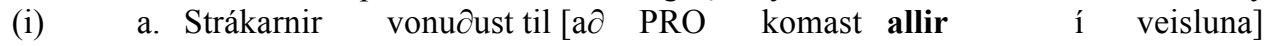
the boys $(\mathrm{N})$ hoped for to (N) get all(Npl.m.) to party

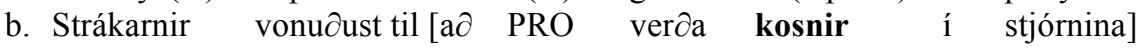
the boys $(\mathrm{N})$ hoped for to $(\mathrm{N})$ be elected(Npl.m.) to the board

Sigurdsson further observes that the Nominative agreement inside these infinitives cannot be attributed to the controlling subject in view of examples like (iia,b), where the matrix subject is not Nominative:

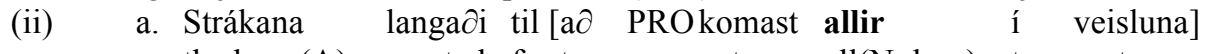
the boys(A) wanted for to get all(Npl.m.) to party

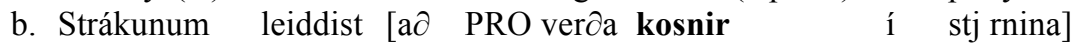
the boys(D) bored to be elected(Npl.m.) to the board

The view that control PRO is fundamentally Nominative is further supported by Terzi's (1992) analysis of subjunctive clauses in the Balkan languages, and by Iatridou's (1993) discussion of similar facts in Greek. See also Watanabe (1993) for related discussion.

${ }^{21}$ We assume that the abstract WH operator of infinitival subject relatives can likewise be made visible by light Nominative Case. 


$$
\operatorname{Max}[\text { AgroP } \underbrace{\operatorname{him}}_{\text {ACC } V} \text { prefers-for [ } \mathrm{VP} \mathrm{t} \text { [CP } \mathrm{t} \quad \text { [AgrsP } \mathrm{t} \underbrace{}_{\text {LIGHT NOM }} \text { to be patient]]] }
$$

This situation contrasts with that in a standard ECM construction like (35), where the embedded subject ( $\mathrm{him}$ ) can be assumed to enter the enumeration bearing only an Accusative Case feature. This single feature is checked in Agr $_{0}$ Spec.

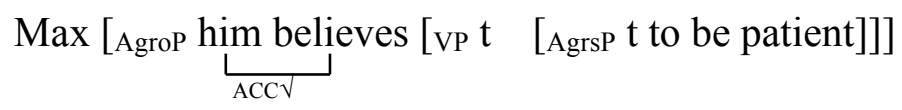

\subsubsection{Blocking Passive in For-to Infinitives}

The double Case-checking apparently required with for-to examples like Max prefers for him to be patient is odd from a general conceptual point of view. Chains are standardly assumed to enter into biunique relations with formal contents like $\varphi$-features, $\theta$-role, and Case, so that each chain receives exactly one set of $\varphi$-features, one $\theta$-role, one Case, and so on. Here, however, biuniqueness seems to break down.

We suggest that the departure from biuniqueness in this analysis is actually less than appears on the surface. In an interesting study of Case marking in subjunctive clauses in the Balkan languages, Watanabe (1993) notes that the ability to get $P R O$ versus a lexical subject depends on the form of the complementizer. In brief, Nominative lexical subjects show up in the presence of a subjunctive complementizer, whereas PRO occurs when the complementizer position in the subjunctive complement is empty. Watanabe (1993) proposes to account for the correspondence by having $\mathrm{T}$ ultimately raise to $\mathrm{C}$ to check off a feature created by Casechecking itself, with different features being checked by different complementizers. Watanabe's basic insight is thus that $\mathrm{T}$ and $\mathrm{C}$ act together to determine the Case possibilities for the subject of an infinitive.

We will adopt Watanabe's general idea, but will employ a slightly different implementation of it. Specifically, we will assume that for and to (and probably their equivalents in subjunctives) should not be viewed as distinct elements, but rather count as a single, "extended" element for the purposes of Case-checking. Suppose that the biuniqueness requirement on Case is understood as a restriction on checking:

- All Case features on a nominal must be checked by the same item.

Then exactly in the instance where the two Case features borne by DP are checked by the same extended element biuniqueness will be satisfied.

Consider now the pair in $(36 \mathrm{a}, \mathrm{b})$ in the light of these points. For convergence in (36a), he need only be assumed to enter the numeration with a single Nom Case: the one that is ultimately checked in the matrix clause. By contrast, in order for (36b) to converge, he must enter the enumeration bearing two Nom features: a light Nom that is checked by to in the embedded clause, and a Nom that is checked by the finite $\mathrm{T}$ in the matrix clause. This difference arises because in (36a), he moves through one Case-checked subject position, whereas in (36b) it moves through two: 

a. He [AgroP $t$ be believed [AgrsP $t$ to be patient]
b. He [AgroP $t$ be preferred-FOR [AgrsP $t$ to be patient]

Our version of biuniqueness now makes the necessary distinction between (34) and (36b). The former involves double Case-checking, however, the two heads - for and to - count as the same element. By contrast with (36b), the relevant Case-checking heads are wholly distinct (finite $\mathrm{T}$ and to), contrary to assumptions; this kind of "true" double-marking and double-checking prevents the derivation for (36b) from converging: ${ }^{22}$

$$
\begin{aligned}
& \text { Extended Case-checker }
\end{aligned}
$$

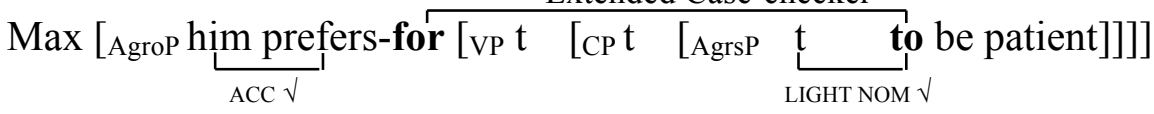

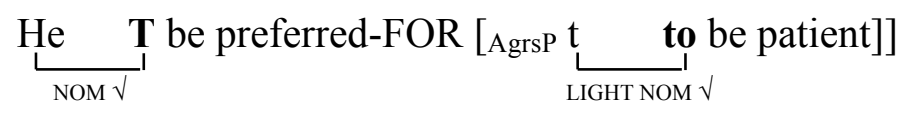

Thus passive is available from the subject of ECM complements, but not from the subject of forto.

With this background account of non-finite complementation, we now address intensional transitives. We will consider concealed infinitival complements and concealed ECM complements separately. Furthermore, within the former, we will distinguish between complements that we analyze as containing an implicit verb HAVE, and those analyzed as containing an implicit verb FIND.

\section{Concealed Infinitival Complements with $H A V E$ 3.1. Restructuring}

As indicated above, intensional transitive examples like (37a) and (38a) appear to be largely synonymous with examples that show a nonfinite complement containing the verb have, as in $(37 b, c)$ and $(38 b, c)$ :

(37) a. Polly hopes/yearns/pines for a cracker.

b. Polly hopes/yearns/pines to have a cracker.

c. Polly hopes/yearns/pines for herself to have a cracker.

a. Polly wants/prefers/desires a cracker.

b. Polly wants/prefers/desires to have a cracker.

c. Polly wants/prefers/desires (for) herself to have a cracker.

The verbs in these examples can all be identified broadly as volitive or volitional. All have to do with the wishes or desires of an agent.

Interestingly, in the Romance languages a number of verbs that are semantically volitional are known to undergo a process that permits complement elements to behave as if they were members of the matrix clause with respect to various syntactic operations. This process is

\footnotetext{
${ }^{22}$ The fact that subjects of for-to infinitives bear light Nom Case also appears to shed light on certain differences in the availability of scopal ambiguity with ECM versus for-to infinitives. See note 37.
} 
known as restructuring, and is illustrated by the Italian data in (39) and (40), from Burzio (1986). (39a) shows that in general, non-finite complements do not allow object clitic pronouns from the complement clause to be moved into the matrix clause. With volitional verbs like volere 'want', however, such clitic promotion is possible (39b). Similarly, (40a) shows that the passivelike impersonal construction in Italian doesn't in general allow promotion of a complement object to matrix subject position. However, (40b) illustrates that, once again, with verbs like want such movement is indeed possible:
a. *Mario lo odia [PRO leggere $\mathrm{t}]$.
Mario it hates to read
'Mario hates to read it.'
b. Mario lo vuole [PRO leggere $t$ ].
Mario it wants to read
'Mario wants to read it.'
a. *Questi libri si odiavano proprio [PRO leggere $\mathrm{t}]$. these books SI hated really to read 'We really hated to read these books.'
b. Questi libri si volevano proprio [PRO leggere t ]. these books SI wanted really to read
'We really wanted to read these books.'

A range of analyses have been proposed in the literature to account for what is going on in cases like (39b) and (40b). One persistent intuition is that these examples exhibit some form of "clause-union" in which a biclausal structure becomes, at some level, uni-clausal (Aissen and Perlmutter (1983), Rizzi (1978)). A complementary intuition is that somehow matrix and embedded predicates are merged to form a single complex form - want-to-read - so that objects of the complement verb become objects of the single, merged form.

A detailed version of the latter idea is advanced by Baker (1988), developing ideas by Burzio (1986). Baker proposes that infinitival complements embedded under restructuring verbs like volere involve a form of verb incorporation. First, the complement VP raises from its source position (41a) into the specifier position of the embedded CP (41b). From this position, the lower verb incorporates into the matrix $\mathrm{V}$ by adjoining to it (41c). As Baker discusses in some detail, incorporation has the effect of extending government domains; whereas the clitic lo was initially governed by the verb leggere 'read', it is now governed by the complex form vuole-leggere wantto-read. This change in government relations allows the object clitic pronoun to move into the matrix clause, as shown in (41d). Similarly for (40b). ${ }^{23}$
a. Mario vuole [CP [PRO [vP leggere lo ]]]
b. Mario vuole [CP [vP leggere lo ] [PRO t ] ]
c. Mario vuole-leggere $[\mathrm{CP}[\mathrm{VP} t \mathrm{lo}][\mathrm{PRO} \mathrm{t}]]$
d. Mario lo-vuole-leggere $\left[\mathrm{CP}[\mathrm{vP} t \mathrm{t}]\left[\begin{array}{lll}\mathrm{PRO} & \mathrm{t}\end{array}\right]\right.$

\footnotetext{
${ }^{23}$ For other recent analyses of restructuring based on different assumptions than those adopted here, see Roberts (1997) and Wurmbrand (1996).
} 


\subsection{Restructuring with Intensional Transitives Selecting for (Hope-for)}

We propose that the restructuring operation observed with Italian volitional verbs is also operative in the wider class of English volitional verbs identified as intensional transitives. Let us consider first verbs like hope, which select an infinitival complement in which the complementizer for must appear. We assume (42a) to have a structure as in (42b), where TO, an inaudible form of to, also assigns light NOM.

\section{a. Polly hopes for a cracker}

b.

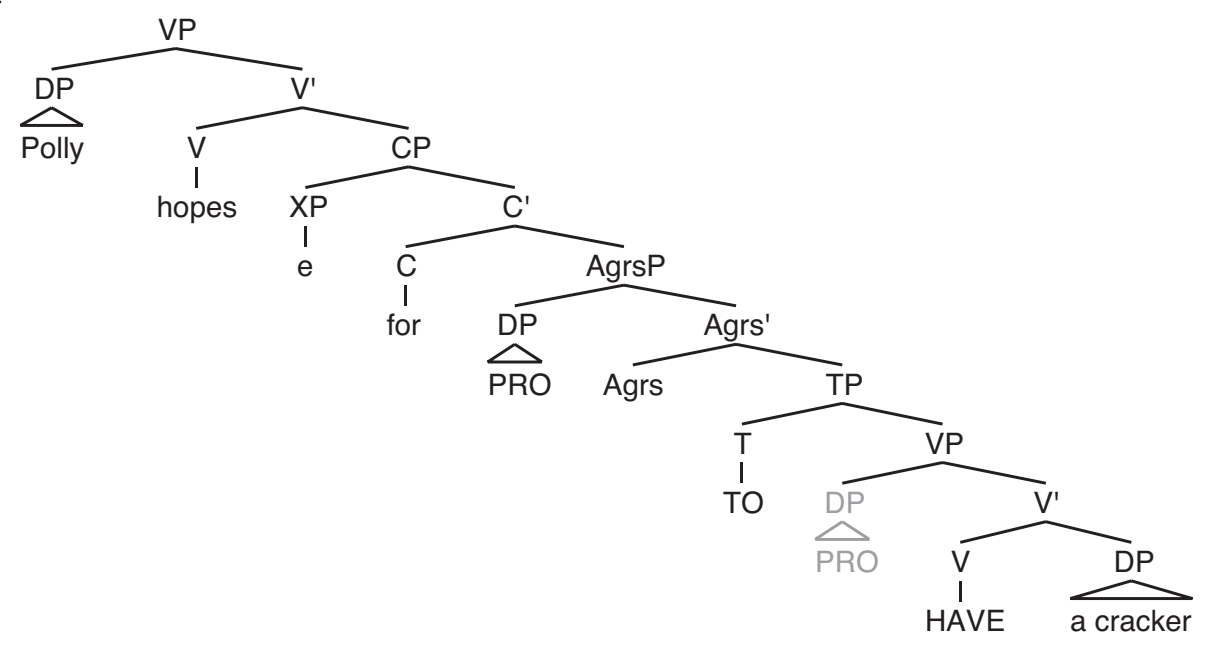

As discussed above, $P R O$ in this structure is assumed to be licensed by a light NOM. Assume further that the silent verb $H A V E$ is a purely semantic element in the sense of bearing only interpretable features ${ }^{24}$ - in particular, assume that HAVE bears no Case feature. This entails that there is no $\mathrm{Agr}_{\mathrm{O}} \mathrm{P}$ present in the embedded infinitival clause. The structure, as it stands, thus presents a dual Case problem: on the one hand, the for complementizer has no obvious way of checking its Case feature; on the other hand, the chain headed by a cracker has no clear way of receiving Case. $P R O$ is unavailable for the former, and HAVE is unavailable for the latter.

Suppose now that this structure is subject to restructuring along the lines of Baker's analysis of the Italian cases. First VP raises to CP Spec position. From this position the inaudible verb HAVE incorporates into the matrix $\mathrm{V}$ forming the complex predicate hopes-HAVE. Furthermore, the complementizer for incorporates into the matrix V, as it always does in infinitival complement structures of this kind (43): ${ }^{25}$

\footnotetext{
${ }^{24}$ See also Parsons (1997) for a recent defense of the proposal that intensional transitives of the want-class embed an implicit HAVE. See Forbes (1997b) for an interesting alternative approach to the whole issue of intensional transitivity, extending the so-called "hidden indexical" theory. We should note that although we treat HAVE in these trees as a primitive element, our analysis not committed to this point. Indeed, we indicated in fn. 5 (see discussion of (iv)) good reasons to think that have is composed of be + a dative element; it appears plausible to extend the same analysis to $H A V E$.

${ }^{25} \mathrm{We}$ will take no stand on the order in which the two incorporations take place, and the exact form of the resulting head-adjunction structure. Accordingly, we represent the derived V-complex by means of a triangle.
} 
(43)

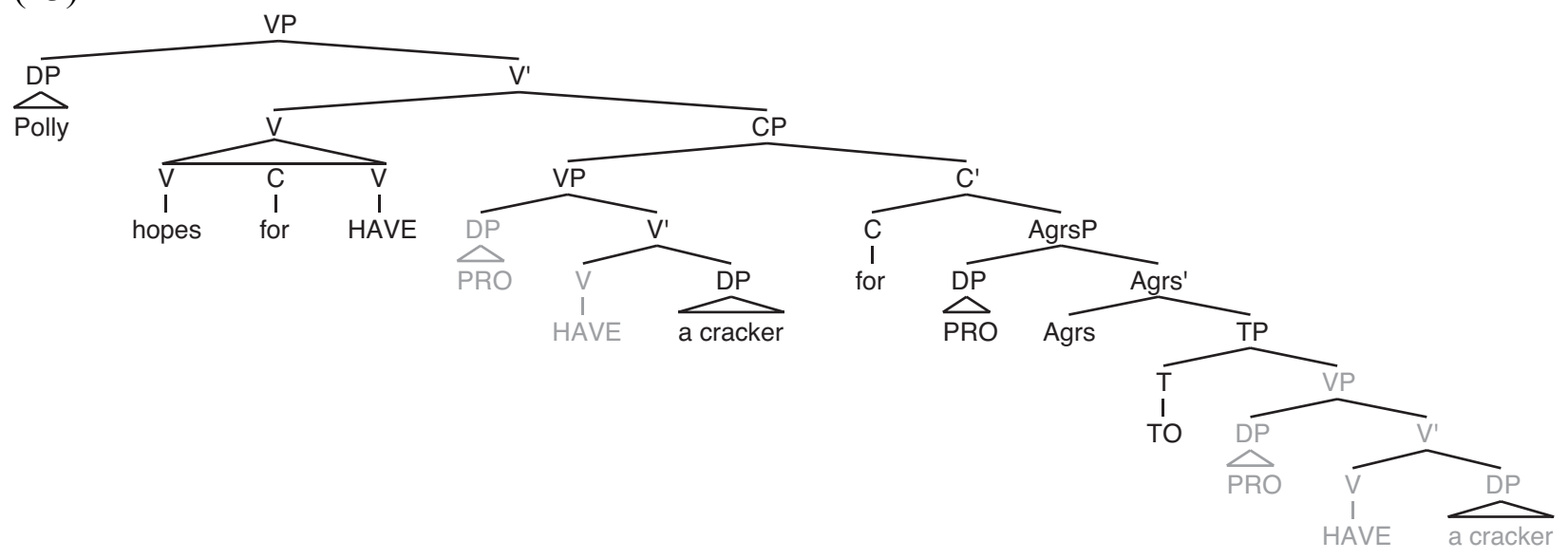

The complex [V hopes-for-HAVE] later raises to $\operatorname{Agr}_{\mathrm{O}}$ (not shown), and a cracker moves to Spec $\operatorname{Agr}_{0} \mathrm{P}$, where Accusative Case features are checked. The Case problems are thus solved and the derivation converges, producing the overt surface form of a transitive Polly hopes for a cracker.

\subsubsection{Consequences of the Restructuring Analysis}

The restructuring analysis delivers a direct account of the features of the intensional transitive construction discussed in section 1 .

Intensionality. With respect to intensionality effects in examples like Polly hopes for a cracker, the latter are now seen to involve clausal complementation, and hence simply show the expected semantic behavior.

Selection \& Binding. The parallel in selectional properties between have and intensional transitives of the want-class (sec 1.1.) and the parallel binding effects (sec 1.2.), are explained by the fact that the apparent object of want (desire, hope for, etc.) is in fact the object of HAVE. The restructuring analysis also explains a related, more subtle feature of the concealed complement account. In general, simple selection for a clausal complement may limit verbs occurring in that complement to some general class(es) (e.g., force and persuade appear to select the general class of eventive verbs and resist statives: Max forced George to jump/ \#Max forced George to like broccoli). But simple selection never is enough to enforce the presence of a specific lexical form. Restructuring provides an answer as to how verbs of the want-class select the particular lexical form HAVE: the two actually come together at LF to form a single complex lexical item. Presumably the features driving incorporation with want (desire, hope for, etc.) are ones checked specifically by $H A V E$ (see below). Indeed, in virtue of the selection of a specific lexical form in the complement clause, a restructuring analysis seems to us unavoidable.

Adverbial Ambiguity. The analysis accounts the familiar adverbial ambiguity in examples like (44a) in a straightforward way (sec 1.3.). The matrix scope reading of tomorrow can be analyzed as in (44b), where tomorrow adjoins to the higher TP; by contrast, the embedded scope reading is analyzed as in (44c) where tomorrow adjoins to the lower TP: 
a. Polly is hoping for a cracker tomorrow

b. [AgrsP Polly [TP is hoping-HAVE for a cracker [CP ... ]] tomorrow ]

c. [AgrsP Polly [TP is hoping-HAVE for a cracker [CP ... tomorrow ]]]

Ellipsis \& Anaphora. The analysis also accommodates the data from VP and comparative ellipsis (sec 1.4.) and propositional anaphora (sec 1.5.) by providing antecedents of the kind needed for both. Examples like the first line in (17a) (repeated below) contain a VP with HAVE ([VP HAVE another sausage]) that is the antecedent of the empty VP in the second line. Similarly, for the comparative ellipsis facts in (18).

$$
\begin{aligned}
& \text { A: Do you want another sausage? } \\
& \text { B: I can't [VP Ø ]. I'm on a diet. }
\end{aligned}
$$

The propositional anaphor it in the second conjunct of (20a) (repeated below) can be understood as referring to the whole clause [CP FOR PRO TO HAVE a horse] contained in the first conjunct:

(20a) Joe wants a horse, but his mother won't allow it.

Passive. The analysis also allows us to understand why passivizing of the object of hope-for succeeds (45a), whereas passivizing the subject of an infinitival complement to hope fails (45b):

a. A cracker was hoped for.

b. *Max is hoped (for) to have a cracker.

As discussed earlier, the subject of an infinitive of this class is assumed to bear light Nominative Case, which is checked against infinitival to. Passivization in (45b) requires Max to bear two instances of Nominative Case that are checked by two distinct heads, which is assumed to be illegitimate. By contrast, since a cracker in (45a) does not move through the embedded Agr Spec position, but is instead raised with VP, it need bear only a single instance of Nominative: the one checked in the upper clause. Hence the derivation converges. ${ }^{26}$

${ }^{26}$ Ludlow (1985) and den Dikken, Larson and Ludlow (1996) suggest an account in which examples like (i) are analyzed as involving passivization of an entire concealed complement clause (iia), on analogy with what is observed overtly in (iib):

(i) John was preferred

(ii) a. [FOR PRO TO HAVE John] was preferred

b. [To have John] was preferred.

This proposal has a number of serious problems, however. As is well-known, movement of clauses under passive is not obligatory; clausal complements have the option of remaining in situ with an expletive appearing in subject position (iiia). If (i) represented passivization of a whole clause, we might expect the same possibility with intensional transitives, contrary to fact (iiib):

(iii) a. It was preferred [ PRO to have John]

b. *It was preferred John.

Second, the clausal subject analysis entails an analysis of examples like (iva) as involving extraction from a sentential subject (ivb); such movements are known to be strongly proscribed, however, as shown in the overt counterpart (ivc):

(iv) a. The man who $[\mathrm{t}$ was preferred $]$ 


\subsubsection{Some Broader Questions}

The analysis advanced here crystallizes a number of important general questions about restructuring that have not been fully addressed in the literature to date. Thus, it is unknown within the general Minimalist Program of Chomsky (1995) what features and feature-checking mechanisms must be taken to drive the incorporation derivation assumed here. These movements include the initial raising of VP to Spec CP (46a); ${ }^{27}$ the incorporation of C into the higher V (46b), and the incorporation of the complement V into the V-C complex (46c). Under the MP, we expect some feature(s) to be responsible for each movement:
a. $\mathrm{V} \quad\left[\mathrm{CP} \quad[\mathrm{vP} H A V E\right.$ a cracker $]\left[\mathrm{C}^{\prime}\right.$ for $\left.\left.[\mathrm{AgrsP} \ldots \mathrm{t} \ldots .].\right]\right]$
b. V-for [CP [VP HAVE a cracker $]\left[\begin{array}{lll}\mathrm{C}^{\prime} & \mathrm{t} & \text { [AgrsP ....... }]]]\end{array}\right]$

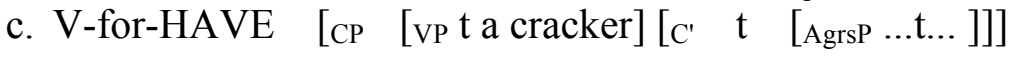

Chomsky (1995) suggests that some LF incorporations might be accounted for by a lexical feature [affix]; forms bearing this feature will need to adjoin to a head for convergence, etc. As we have noted, however, the specific cooccurrence relation between verbs of the want-class and

b. *The man who [FOR PRO TO HAVE $\mathrm{t}$ ] was preferred

c. *The man who [to have $\mathrm{t}$ ] was preferred

More generally, an analysis where the apparent object of an intensional transitive remains in situ within the concealed complement clause raises difficulties for Case-checking in cases like (va), which must be analyzed as (vb):

(v) a. Polly hopes for a cracker

b. Polly hopes [for PRO TO HAVE a cracker]

There are the double questions of what checks the Case of for and a cracker. On the restructuring analysis these questions are answered together; on an analysis without restructuring they are not.

Another proposal entertained by den Dikken, Larson and Ludlow (1996) is that these verbs may admit multiple clausal complement structures. So, for example, it was suggested that John wants a donkey, might be ambiguous between the following three structures, where V2 and V1 are implicit transitive and intransitive verbs, respectively, and PRED is an implicit small clause predicate:

(vi) John wants [PRO V2 a donkey]

(vii) John wants [a donkey V1]

(viii) John wants [a donkey PRED]

It was then argued that the source of the passive form was from one of the latter two structures. In the specific case of wants it was held that the passive form came from an implicit small clause structure, as in John is wanted (dead or alive). Likewise it was held that the passive forms appearing with seeks, looks for, etc. had their origin from a structure in which the NP was in subject position of the implicit clause.

We are now inclined to think that as a general strategy this cannot be right. Most of these structures clearly favor a single interpretation, as opposed to several. For example, although both infinitives and SCs are possible with, say, prefer, the surface transitive construction is not ambiguous. (xi) is synonymous with (ix) but not with (x):

(ix) Someone prefers to have that candidate

(x) Someone prefers that candidate dead

(xi) Someone prefers that candidate

Similarly, (xii) is not synonymous with (x) (or (x) with any replacement SC predicate):

(xii) That candidate is preferred.

Accordingly, it is not clear how appeal to structural ambiguity helps. It also seems that the surface transitive version of desideratives is (notwithstanding the wanted-poster reading discussed above) uniformly understood as containing have.

${ }^{27}$ One possible alternative is that it is not VP, but rather the TP headed by TO that raises into Spec CP, and checks features on for. This proposal is plausible given the evident dependence between complementizer in infinitives and the embedded tense. 
the lexical form HAVE suggests a specific feature-checking relation between the matrix and complement V. Furthermore, in virtue of the unacceptability of passive examples like *A cracker is wanted to be had, it is necessary for us to assume that only HAVE carries the relevant feature in English and hence only clausal complements containing HAVE undergo restructuring. The answers to these questions evidently wait upon a more detailed understanding of restructuring generally within the current framework. For the present we will simply assume, given the reality of the restructuring phenomenon, that some answer can be given and that this answer will extend to the constructions treated here, obviously a non-trivial assumption.

A more concrete issue concerns the level at which the incorporations proposed here take place. If incorporation takes place before Spell Out, then we get some purchase on well-known "complementizer doubling" phenomena occurring with certain infinitives. (47a, b) give familiar cases where (the infinitival complementizer) for shows up twice in association with a single complement. A natural account of this within Minimalism is that incorporation, like all movement, involves copying, and that $(47 \mathrm{a}, \mathrm{b})$ involve both the head and the tail in the movement chain (for, for) being phonetically realized:

(47) a. [for Bob to be elected] was fervently hoped for in some segments of the population.

b. What Max is praying for is [for Lyndon to win].

Nonetheless, the situation is not straightforward. Although the complementizer may incorporate pre-Spell Out in the overt clausal construction, in the surface transitive construction, for and its trailing DP can be fronted together without doubling (48a). Notice, furthermore that for $+\mathrm{DP}$ can be fronted with its trailing adverbial, without loosing the reading in which the adverb modifies the implicit $H A V E$ verb (48b). In view of this, it seems we must analyze examples like (48a) as involving the fronting of the entire complement clause as in (48c), where the source-position copy is indicated in italics:

(48) a. [For such things] one should never hope (??for).

b. [for a cracker tomorrow] Polly is hoping.

c. [For PRO HAVE such things] one should never hope [for PRO HAVE such things]

Presumably, whereas the fronted elements are active at PF, at LF it is the source-copy portions that undergo incorporation and that are relevant for semantic interpretation. Hence we must assume that the incorporations involved with intensional transitives occur at LF.

\section{3. $\quad$ Restructuring with Intensional Transitives Selecting FOR (Desire)}

The analysis given to hope also extends to verbs like want, desire and prefer. Thus Polly desires a cracker can be given the analysis in (49a), which is identical to that of hope, except that the inaudible complementizer FOR occurs. As before, VP raises to Spec CP (49b), from which position HAVE incorporates into desire (49c). The complementizer then incorporates yielding (49d):

(49) a. Polly [vP desires [CP [C, FOR [AgrsP PRO [vP HAVE a cracker]]]]

b. Polly [vp desires [cP [vp HAVE a cracker] [c, FOR [AgrsP PRO t ]]]]

c. Polly [vp desires-HAVE [CP [vp t a cracker] [C, FOR [AgrsP PRO t ] ]]] 


\section{d. Polly [vp desires-HAVE-FOR [CP [vp t a cracker] [C' t [AgrsP PRO t ]]]]}

The main difference between this class of verbs and the previous one concerns the realization of the complementizer for. For is obligatory with hope in the surface transitive construction (50a), but forbidden with want, desire and prefer (50b). Correlatively, in clausal complement constructions with an overt subject, for is obligatory with hope (51a), but optional with want, desire and prefer (51b). Finally, when an overt clausal complement is fronted, hope permits doubling of for (52a), but want, desire and prefer flatly forbid it (52b):

(50) a. Polly hopes *(for) a cracker

b. Polly wants/desires/prefers (*for) a cracker

(51) a. Polly hopes *(for) a cracker to arrive.

b. Polly wants/desires/prefers (for) a cracker to arrive.

(52) a. [For Polly to be patient] is what Max will hope for

b. [For Polly to be patient] is what Max will want/desire/prefer (*for)

In other words, we get the following pattern in for versus FOR:

- verbs requiring for in their overt complementation require for in their covert complementation.

- verbs allowing FOR in their overt complementation forbid for in their covert complementation.

The basic generalization here seems to be that the derivation must choose FOR wherever possible. Although we don't have a secure explanation for this pattern at present, it may fall under some version of Pesetsky's (1995) "Telegraph Principle" according to which derivations minimize phonology. What we seem to see in the distribution of the infinitival complementizer is a default preference for the unpronounced form.

\subsection{Complex Determiners and the Concealed Clause Analysis}

An interesting challenge to the concealed clause analysis of want and desire-type verbs is raised by Zimmermann (1993), who draws attention to pairs like (53), involving a negative NP in object position: ${ }^{28}$

(53) a. Max needs no bananas

b. Max needs to have no bananas

Although syntactically very close on our analysis, (53a) and (53b) diverge in meaning. Consider the situation where Max actually gets (and therefore has) bananas. (53a) has a reading on which Max's needs are met in these circumstances: he doesn't need any bananas, but he gets them anyway. By contrast, (53b) has no reading on which Max's needs are met in the situation

\footnotetext{
${ }^{28}$ This argument is repeated in Moltmann (1997).
} 
described. (53b) asserts Max to need that he have no bananas.

A similar effect arises with object NPs containing at most:

a. Max needs at most five bananas

b. Max needs to have at most five bananas

Consider the situation where Max actually gets (and therefore has) six bananas. Max needs as expressed by the salient reading of (54a) are met in these circumstances: he doesn't need more than five bananas but he gets them. But Max's needs as expressed by (54b) are not met in these circumstances. What he needs is to have at most five bananas, and his needs are not met if he gets six. Zimmermann (1993) takes the contrast between $(53 a) /(54 a)$ and $(53 b) /(54 b)$ to show that there is no derivational relation between intensional transitive need and clausal complement need, and hence that the two require a different syntax and distinct semantics. We believe this conclusion is hasty however. We will now sketch an alternative, clausal approach that not only gets the facts in question but others besides.

The basic insight of our alternative is due to Klima, who proposed in a classic paper (Klima (1964)) that negative NPs of the form no-N divide into two separate components: a sentence negation and an indefinite. Klima's point was suggested in connection with the equivalence of (55a) and (55b). One way of spelling out Klima's proposal concretely is to think of (55a) along the lines of (55c), where the negative determiner decomposes into an abstract a sentence negation NEG together with an indefinite word no having the force of any. ${ }^{29}$
a. Max had no bananas
b. Max didn't have any bananas
c. Max NEG had [ t no ] bananas

We may assume the NEG to raise to the position of sentential negation at LF. Ultimately, then, (55a) possesses a form analogous to (55b), namely, (55c).

In general, NEG V...any- $\mathrm{N}$ is equivalent to $\mathrm{V}$...no-N. There is one prominent place where the equivalence fails, however. This is the case where more than one sentence is present (more than one clause), and hence more than one potential location for sentential negation. (56a) is equivalent to (56b), but not to (56c).
a. Max needed to have no bananas
b. Max needed not to have any bananas
c. Max didn't need to have any bananas

The nonequivalence of $(56 \mathrm{a}, \mathrm{b})$ versus $(56 \mathrm{c})$ is accounted for if the negation in $n o-\mathrm{N}$ is confined to the smallest sentence containing it. More specifically in terms of the proposal made above, it is accounted for if a negation must raise to the closest position of sentential negation:

(56a') Max need [PRO to have [ NEG no ] bananas

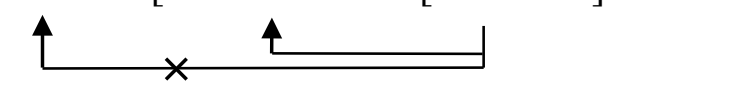

Consider now the case of intensional transitives (57). We noted that, unlike (56a), (57a)

\footnotetext{
${ }^{29}$ See Ladusaw (1992) for a related proposal.
} 
has a (preferred) reading equivalent to $(57 \mathrm{~b})$.
a. Max needed no bananas
b. Max didn't need any bananas

In our analysis the nonequivalence between (56a) and (57a) is accounted for in the following way: the latter, unlike the former, undergoes restructuring, which raises the VP containing the negative quantifier to Spec CP (58a-c). From this point, the closest position of sentential negation to which NEG can raise is in the upstairs clause $(58 \mathrm{~d}):^{30}$
a. Max [vp needs [cP [c, FOR [AgrsP PRO [vp HAVE NEG no bananas]]]]
b. Max [vp needs [CP[vp HAVE NEG no bananas][C,FOR [AgrsP PRO t ]]]]
c. Max [vp needs-HAVE-FOR [CP[vP t NEG no bananas][C, $t$ [AgrsP PRO t $]]]$
d. Max [vp needs-HAVE-FOR[CP[vP t NEG no bananas][C, t [AgrsP PRO t]]]]

Thus the possibility of a reading of (57a) equivalent to (57b) follows from the fact that in the intensional transitive construction the infinitive VP has restructured, allowing the NEG to be positioned the higher clause.

We suggest a similar line for the at most cases. Consider (59a, b). It seems to us that these two sentences are truth-conditionally equivalent, and that in general at most V...QNP is equivalent to V...at most-QNP. Our proposal is that at most-Q NPs, like negative NPs, consist of two syntactic parts - at-most and Q - and that former takes scope independently of the latter at LF.
a. Max has at most five bananas
b. Max at most has five bananas
c. Max at most has [ $t$ five ] bananas

Specifically, we assume that at most in (59a) raises at LF to the position occupied by at most in (59b). Ultimately, then, (59a) has a logical form analogous to (59b), namely, (59c).

As in the case of negation, the equivalence between at most V...QNP and V...at mostQNP fails in clausal complement contexts. (60a) is equivalent to (60b), but not to (60c).

(60) a. Max needs to have at most five bananas

b. Max needs to at most have five bananas

c. Max at most needs to have five bananas

30 (57a) also has the narrow scope reading associated with (56a, b), which (57b) lacks. In our analysis this reading is obtained as a reconstruction effect under the Copy Theory of Movement discussed earlier. On this theory, the raising of VP in restructuring actually leaves a copy VP in the downstairs clause (i). We assume that the downstairs reading is obtained by taking the lower copy as the syntactically active one at LF, raising its NEG to the lower position for sentential negation (ii) :

(i) $\operatorname{Max}[\mathrm{vp}$ needs [CP [vp HAVE NEG no bananas] [C, FOR [AgrsP PRO TO HAVE NEG no bananas ]]]]

(ii) $\quad \operatorname{Max}\left[{ }_{\mathrm{vp}}\right.$ needs [ ${ }_{\mathrm{CP}}[\mathrm{vp}$ HAVE NEG no bananas] [C, FOR [AgrsP PRO TO HAVE NEG no bananas ]]]] 
We assume this non equivalence reflects the same kind of scope limitation observed with negatives. That is, we assume that at most in (60a) must raise to the closer position occupied by at most in (60b), and not to the more distant position occupied by at most in (60c):

(60a') Max needs [PRO to have [ at most five ] bananas

Our diagnosis of the situation with at most QNP in intensional transitives is likewise identical to that given for negation. Unlike (60a), (61a) can have a reading equivalent to (60b):

a. Max needs at most five bananas

b. Max at most needs five bananas

The greater scope possibilities for (61a) arise from the crucial fact that the latter undergoes restructuring, which raises the VP containing the at most-Q NP to Spec CP (62a-c). From this point, the closest appropriate position to which at most can raise is in the upstairs clause.

\section{A Scope Asymmetry}

The clausal complement + restructuring analysis appears to shed light on an interesting asymmetry in accessibility of upstairs versus downstairs scopes for need versus want. Consider the preferred scopes for at most and negation in the following pairs:

(62) a. Max needs at most two visitors.

b. Max wants at most two visitors.
a. Max needs no visitors.
b. Max wants no visitors.

For the two English speaking authors of this paper (RKL and PL) there is no detectable difference in how the scope of at most is understood in (62a) versus (62b). For us, both favor the reading equivalent to Max at most needs/wants two visitors. By contrast, $(63 \mathrm{a}, \mathrm{b})$ show an asymmetry in how the scope of negation is understood. (63a) favors the reading where it is understood equivalently to (64a) with high scope for negation, whereas (63b) favors the reading where it is equivalent to (64b) with low scope:
a. Max doesn't need to have any visitors
b. Max wants not to have any visitors

In the clausal analysis, this asymmetry can be attributed to the independent fact that want is a Neg-lowering verb and need is not. That is, it reduces to the fact that with clausal want, a Neg occurring in the matrix clause is preferentially construed in the complement clause. Thus (65) is not generally understood as asserting a lack of desire on Max's part to have visitors; rather it is read as asserting Max's desire to have no visitors. 
Max doesn't want to have any visitors.

What seems to be going on here is that even when the negative NP in (63b) raises into the upstairs clause under restructuring, the upstairs negation is still construed with the lower Neg position, as in (65), accounting for its equivalence to (64b). This surprising contrast would seem to escape an analysis that doesn't postulate a hidden clausal complement since there is no clear way to invoke the Neg-lowering property of clausal want under such an approach.

\section{Concealed Infinitival Complements with FIND (look for, seek)}

The analysis given to volitional verbs like hope, want, desire and prefer also extends to the class of predicates originally discussed in Quine (1960), namely to verbs of searching. These include seek, search-for, look for, and hunt-for. Quine noted that simple transitive constructions with these predicates can be paraphrased approximately with try-to-find; hence (66a-c) are largely equivalent to (67a-c), respectively.

(66) a. Max is seeking a new secretary.

b. The Coast Guard is now searching for survivors.

c. Ctesias is hunting for a unicorn.
a. Max is trying [CP PRO to find a new secretary].
b. The Coast Guard is now trying [CP PRO to find survivors].
c. Ctesias is trying [CP PRO to find a unicorn].

Partee (1974) questions a literal derivation of the first group from the second given that this would entail obliterating all meaning differences between seek, search-for, hunt-for, etc. However, a less mechanical implementation of Quine's idea is available in which these distinctions are not lost. Note that surface transitive constructions like (68a) can be paraphrased with infinitives embedded under try, as in (68b), but they can also be paraphrased as in (68c):
a. Max is looking for/seeking survivors.
b. Max is trying [CP PRO to find survivors].
c. Max is looking/seeking [CP PRO to find survivors].

This result is somewhat surprising insofar as look-for and seek appear to be equivalent to try to find in (68a), but equivalent to try alone in (68c) since 'find' is contributed independently. One possibility, of course, is that there are simply two different verbs in each case: for example, one look, an intensional transitive with the meaning 'try-to-find', and the other a distinct clause-taking look with the meaning 'try'. An alternative, however, is that there is just one verb here, equivalent to try, and that the additional component of meaning found in (68a) results from incorporation of an abstract, independent predicate equivalent to that found overtly in (68c).

We suggest the latter analysis. More precisely, we propose that intensional transitive look and the other verbs of this class select a clausal complement containing an abstract predicate FIND. As in the analysis of the volitional class, the VP containing the object first moves to CP Spec (69b). From there, the complement V (FIND) and complementizer incorporate into the matrix verb (look) (69c). Finally, the complement object (survivors), raises to Agr $_{\mathrm{o}}$ Spec (69d), 
yielding the final form: ${ }^{31}, 32$

(69) a. Max is [vP looking [CP [C, for [AgrsP PRO to [vP FIND survivors]]]]

b. Max is [vP looking [CP [vP FIND survivors][C, for [AgrsP PRO to t ]]]

c. Max is [vp looking-FIND-for [ $\mathrm{CP}_{\mathrm{VPP}} \mathrm{t}$ survivors][C $\mathrm{t}$ [AgrsP $\mathrm{PRO}$ to $\left.\left.\mathrm{t}\right]\right]$ ]]

d. Max is [AgroP survivors looking-FIND-for $\mathrm{t}\left[\mathrm{CP}[\mathrm{VP} t]\left[\mathrm{C}^{\prime} \mathrm{t}[\right.\right.$ AgrsP PRO to $\left.\left.\mathrm{t}]\right]\right]$

Intensional transitives with concealed FIND appear to realize a possibility noted earlier with respect to Case-checking. Recall the discussion of $(27 \mathrm{~b})$, repeated below in a more schematic form as (70):
a. $\mathrm{V} \quad \mathrm{NP} 1 \quad[\mathrm{CP}$ for $[\mathrm{AgrsP} \ldots \mathrm{NP} 2 \ldots]]$

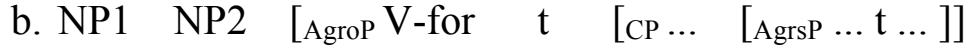

Assuming that the verb (V) contains its own independent Accusative Case feature, incorporation of for would yield the possibility of two nominal complements (NP1) checked by the V-for

\footnotetext{
${ }^{31}$ Getting ahead of ourselves slightly, the treatment of intensional transitive seek/look-for and propositional seek/look-for plus find raises questions about the alleged transitivity of find (see Ludlow 1985, who attributes the observation to Josef Stern, and Kaplan 1986). The issue is that even if the site of Troy is also the location of Joe's Car Wash, (ii) does not follow from (i).
}

(i) Max found Joe's Car Wash.

(ii) Max found the site of Troy.

This in turn raises questions should we want to defend a general thesis about the link between intensional contexts and clausal complements (see section 6 for discussion of this possibility).

The nature of find bears on a range of interesting issues that we cannot go into here apart from a few suggestions for further investigation. One possibility is that find is itself ambiguous between an extensional find and an intensional one. This would be consistent with the facts in languages such as Dutch, which has two distinct lexical entries vinden 'to locate, to stumble upon', and zoeken 'to find after seeking', for the extensional and intensional senses respectively. By hypothesis, then, the implicit verb showing up in abstract clausal complements would be the extensional find.

Even if find is shown to be intensional (and we doubt it will be), a subsequent clausal analysis of find is certainly possible -- one in which find takes an implicit WH-clause. Consider (iii) for example.

(iii) Holmes seeks/looks for the murder of Smith.

If (iii) is true, then Holmes is attempting to discover who the murder is, i.e. that the murder is X. Here's one way to gloss it.

(iv) Holmes seeks [PRO to find WHOx [the murder of Smith to be $\mathrm{x}]]$

Other cases involve different kinds of sought-after discoveries. So if Holmes has identified the murderer, his search may be over. Now it is Scotland Yard's turn:

(v) Scotland Yard seeks [PRO to find WHEREx [the murderer of Smith to be at $\mathrm{x}$ ]

Again, we cannot pursue these possibilities here. The crucial thing to see at this point is that each of these paths allows us to avoid treating the implicit find as an irresolvable intensional transitive predicate.

${ }^{32}$ The restructuring analysis of English try/look-for/seek may appear questionable given that the Italian counterparts of these verbs do not show restructuring properties; the case of try/look-for/seek diverges from want in this respect. However, in an interesting study of restructuring constructions, Wurmbrand (1996) argues that German versuchen, 'try', is a restructuring verb on the basis of the availability of "Long Distance Scrambling" (i):

(i) weil der Hans $[\text { das Bier }]_{i}$ versuchte $\left[t_{i}\right.$ zum Bahnhof zu bringen ]

since Hans the beer tried to-the train station to bring

'since Hans tried to bring the beer to the train station'

On the basis of this, it appears that a restructuring analysis with try/look-for/seek must be available in principle, although cross-linguistic variation with respect to the overt clausal cases must be left as an unsolved problem at this point. 
complex: an object (NP1) whose Case is checked by V, and an complement arising in a concealed clause (NP2) whose Case is checked by the incorporated prepositional complementizer (for). Note that whereas NP2 arises in the concealed clause, and is predicted to be intensional, NP1 arises in the main clause and is predicted to be extensional.

With these points in mind, compare $(71 \mathrm{a}, \mathrm{b})$. The former contains a single intensional complement ((for) a unicorn), but the latter contains both an intensional complement and an extensional object (the forest). ${ }^{33}$

a. Max searched for a unicorn.

b. Max searched the forest for a unicorn.

We suggest that (71b) exemplifies the theoretical possibility in (70). The extensional object arises in the matrix clause and the intensional NP within the concealed complement clause as an object of FIND (72a). At Logical Form, both the forest and a unicorn raise to Spec of Agr $_{0}$ where their Cases are checked by the separate contributions of the searched-FIND-for complex (72b):

(72) a. searched [the forest] [CP for [AgrsP ... [ FIND a unicorn]]]

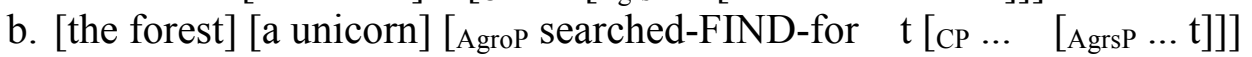

\subsection{Lack of Adverbial Ambiguities}

Partee (1974) expresses doubt about the biclausal analysis of look-for and seek given the absence of adverbial ambiguities of the kind observed with volitional verbs. Thus if the acceptability of (73a), containing tomorrow plus a matrix past tense, arises through the potential embedded attachment for the adverb, then we might expect (73b) to be similarly acceptable. But evidently it is not.

(73) a. Max wanted a unicorn tomorrow.

b. \#Max looked for a unicorn tomorrow.

On further reflection, however, it is clear that the unacceptability of (73b) cannot be due to a lack lower attachment possibility. To see why, simply note that (74a), which contains an overt infinitival complement, is just as unacceptable as (74b). Evidently, attachment (74b) can be ruled out on grounds of the temporal clash; but notice that (74c) must be excluded on independent grounds; something else must block the lower attachment:

(74) a. \#Max tried to find a unicorn tomorrow

b. Max tried [PRO to find a unicorn] tomorrow

c. Max tried [PRO to find a unicorn tomorrow]

\footnotetext{
${ }^{33}$ The extensionality of the first object of search is verified by mutual entailments of pairs like (ia, b), and by the falsity of sentences containing a non-denoting term (Mirkwood Forest) in that position (ii):

(i) a. Max searched London for a crown.

b. Max searched the capital city of England for a crown.

(ii) Max searched Mirkwood Forest for a ring.
} 
In fact, (74c) seems to be ruled out by general pragmatic considerations on what it means to try to find something. In brief, it seems to us that while one can seek something today with the goal of finding it by tomorrow, one cannot seek something today with the goal of finding it tomorrow. ${ }^{34}$ If you seek or look for something, and you achieve the object as a result of your search, then the time of your obtaining the object must overlap with the time of the search. The following thought experiment supports this claim. Suppose a plane goes down in the Amazon jungle and we are interested in finding its survivors. We consult an oracle who tells us that we will not find the survivors today, but if we search diligently today, we will find the survivors tomorrow. If we really believe the oracle and go out searching today, are we really searching, or are we just going through the motions? It seems plain to us that the latter is true. One cannot truly search at a given time with the goal of finding at a different time.

\subsection{Preference for $\mathrm{De} R e$ Readings}

Zimmermann (1993) questions a clausal complement analysis of seek class verbs on the basis of an alleged absence of de dicto readings in intensional transitives with quantified objects. Thus whereas (75a) is admitted to have a perfectly respectable de dicto reading in which Alain is searching with the general aim of finding every comic book, (75b) is held to lack such a reading and to have only the de re interpretation where for each comic book, Alain is searching for it:

a. Alain is trying to find each comic book.

b. Alain is seeking each comic book.

On the basis of the claimed distinction, Zimmermann argues for a different analysis of intensional transitive verbs as operating on directly on properties.

Although we agree that de re readings are in general more prominent with intensional transitives than their full clausal counterparts, we reject Zimmermann's broad claim that de dicto readings are simply unavailable with quantifiers in surface object position. It seems to us plain, for example, that (76a) and (76b) have readings in which the strong quantified object is understood de dicto. Thus the former can be understood so that Alain seeks to locate all spiders in his home without having, for each spider, the aim of finding it; similarly for (76b). The point is also made by (77) and (78), attributed by Zimmermann to Dowty and to Rooth (1985), respectively. Here again, a de dicto reading of the surface object is natural. ${ }^{35}$

(76) a. Alain is seeking every spider in the house.

b. Alain is seeking at most five spiders.

(77) I have looked for every typo in the manuscript.

(78) For her term project, Mary needs every book by some Norwegian.

\footnotetext{
${ }^{34}$ This discussion is repeated from den Dikken, Larson and Ludlow (1996).

${ }^{35}$ In response to the Dowty example, Zimmermann alludes to unexplained properties of the quantifier every. It seems to us, however, that the strong preference for de re readings in Zimmermann's examples results from his persistent use of the quantifier each, which notoriously favors wide scope construals.
} 
These points suggest that the correct idealization of the data is that full clausal complementation structures show both de dicto and de re readings, but with intensional transitives a matrix (and hence de re) construal is more accessible, and often strongly preferred. On our analysis, this difference finds a natural analog in the distinction between (79a) and (79b):

a. Some juror believes every defendant is guilty.

b. Some juror believes every defendant to be guilty.

As discussed by Postal (1974) and Borkin (1984), ECM structures exhibit a much stronger availability of wide scope/de re construals than tensed clausal complements. Thus whereas it is very difficult to understand (79a) with every defendant taking scope over some juror, this reading is quite natural in (79b) and indeed preferred to the reading where every defendant is read narrowly with respect to believe. ${ }^{36}$ As noted in Lasnik and Saito (1981), the current theory can attribute this difference to the fact that with the latter, but not the former, there is A-raising of every defendant into the matrix clause (at LF) to check Case. A-raising overcomes the usual clause-boundedness of $\mathrm{QR}$, but nonetheless preserves the scope possibilities of the raised item, hence the continued possibility of ambiguity in (79b).

Consider now the parallel point for the pair in (80). With the latter there is complement VP movement at LF, with the object each comic book moving into $\mathrm{Agr}_{\mathrm{o}}$ Spec (81). The object thus raises into the matrix clause:

(80) a. I am seeking to find each comic book.

b. I am seeking each comic book.

\section{I am [AgroP each comic book looking-FIND-for [ $\left.\left.{ }_{\mathrm{CP}}[\mathrm{vP} t]\left[\mathrm{C}^{\prime} \mathrm{t}[\mathrm{AgrsP} P R O \mathrm{t}]\right]\right]\right]$}

As in the ECM cases, we expect A-raising to preserve the downstairs construal, but ceteris paribus we also expect the same general enhancement of wide scope de re construal found in the ECM case. Thus we account for the differential scope preferences identified by Zimmermann $(1993) .^{37}$

\footnotetext{
${ }^{36}$ Postal (1974, pp. 222-225) actually claims de dicto construals to be unavailable in ECM constructions. Thus he claims that the (a) members of (i) and (ii) have either a narrow or wide scope reading of the embedded subject, but that the (b) examples permits only the wide scope reading:

(i) a. The FBI proved that few students were spies.

b. The FBI proved few students to be spies.

(ii) a. Melvin showed that none of the formulas were theorems.

b. Melvin showed none of the formulas to be theorems.

While we agree that the wide scope construal is much more accessible and indeed strongly favored in the (b) examples, we also find a less-preferred narrow scope reading with these forms. See also Borkin (1984).

${ }^{37} \mathrm{An}$ interesting question is raised for our analysis by the fact that quantified subjects of want-type verbs do not routinely show the same scopal possibilities as quantified subjects of believe-type verbs, even when the complementizer for is absent. Thus construal of every defendant with wide scope appears to be more difficult in (ia) than in (ii) (and certainly more difficult in (ib)). This appears mysterious if both involve LF raising to Agr $_{0}$ :

(i) a. Some juror wants every defendant to be acquitted.

b. Some juror wants for every defendant to be acquitted.

(ii) Some juror believes every defendant to be guilty.

However, despite the fact that both (ia) and (ii) involve rasing in our analysis, there is an important difference between (ia) and (ii). With believe, the subject raises to Spec Agr $_{\mathrm{o}}$ from a non-Case position, whereas with want the
} 


\section{Concealed ECM Complements (imagine, picture)}

Intensional transitives of volition and search are analyzed here as restructuring constructions, parallel to what one finds in Romance languages. A different analysis holds, we believe, for the class of intensional transitive verbs including imagine, picture, paint and expect in one of its syntactic realizations (see below). These verbs do not take control complements, but rather select a small clause (82a-c), or an ECM infinitive (82d): ${ }^{38}$
a. i. Max imagined a new car.
ii. Max imagined [a new car in his driveway]
b. i. Max pictured a unicorn.
ii. Max pictured [a unicorn in his yard]
c. i. Max painted a bowl of fruit.
ii. Max painted [a bowl of fruit on a table]
d. i. Mary is expecting a bus.
ii. Mary expected [a bus to arrive]

Like their clausal counterparts, the surface transitive constructions allow the postverbal NP to be non-denoting without inducing falsehood (Max imagined a vampire). Likewise substituting identically referring postverbal NPs needn't preserve truth (cf. Max imagined Boris Karloff versus Max imagined Bill Pratt).

\subsection{The Stage-level Restriction}

Our proposal is that the verbal complements in (82a.i-c.i) are fundamentally small clause structures with a concealed predicate X. More precisely, we propose that what follows verbs of this class is a small clause structure containing a stage-level predicate (83), in the sense of Carlson (1977). On this view, a sentence like (82a.ii) has the analysis in (84a), where the verb raises to $\mathrm{Agr}_{0}$ at $\mathrm{LF}$ and the subject of the small clause raises to Spec $\mathrm{Agr}_{0}$. Similarly, in (82a.i) imagine raises to $\mathrm{Agr}_{\mathrm{o}}$ and $a$ car raises to $\mathrm{Spec} \mathrm{Agr}_{0}$.

[vp imagined [DP $\left.\mathrm{X}_{\mathrm{STAGE}-\mathrm{LEVEL}}\right]$ ]

a. Max [Agrop [a new car] imagined [vp $\mathrm{t} \quad$ [AgrsP $\mathrm{t}$ [PP in the driveway ]]]]

b. Max [AgroP [a new car] imagined [vp $\quad \mathrm{t} \quad\left[\begin{array}{lll}\mathrm{t} & \left.\mathrm{X}_{\text {STAGE-LEVEL }}\right]\end{array}\right]$

The restriction on complement of verbs of this class to stage-level predicates is motivated

subject raises from a position where light Nominative Case is checked. As is shown by infinitival relative constructions ( $A$ man $O P_{i} t_{i}$ to mow the lawn), light Nominative Case is sufficient to license a variable. The upshot is that in (ia), the quantifier every defendant will (after deletion of intermediate traces) be bound to an A-position in which Case is checked (a variable position), whereas in (ii) every defendant will be bound to an A-position in which Case is not checked. We suggest that this is the source of the difference in readings. With respect to scope, (ia) (after deletion of intermediate traces) basically behaves like a QR structure, where the quantifier moves from a Caseposition. By contrast, (ii) maintains the status of a raising construction.

${ }^{38}$ Forbes (1997b) takes verbs of the imagining-picturing class as presenting a special challenge for propositional analyses of intensional transitives. This view appears to be based on an incomplete appreciation of the possibilities for clausal complements in natural language, which includes small clauses. 
by the apparent correlation in (85) and (86) below. As first noted (to our knowledge) by Pesetsky, verbs like believe, judge and consider seem to resist typical stage-level predicates like available and on the boat in favor of individual-level predicates like altruistic and intelligent $(85 \mathrm{a}-\mathrm{c}):^{39}$

a. ??Max believes Bill available/on the boat.

Max believes Bill altruistic/ intelligent.

b. ??Max considers Bill available/ on the boat.

Max considers Bill altruistic/ intelligent.

c. ??Max judges Bill available/on the boat

Max judges Bill altruistic/ intelligent.

Observe now also that simple transitives with believe, judge and consider also do not show a concealed clause reading in their transitive form. For example, (86a) Max believed Bill does not mean that Max believed Bill to have some property, rather it means that Max believed Bill spoke truthfully. Likewise, (86b) Max considered Bill does not mean Max considered Bill to be something, rather it means (roughly) that Max thought about Bill, for example, with regard to whether he should be selected for the team.

a. Max believed Bill. ( $\neq$ 'Max believed Bill to be PRED')

b. Max considered Bill.

(? $\neq$ 'Max considered Bill to be PRED')

c. Max judged Bill.

( $\neq$ 'Max judged Bill to be PRED')

Notice further that in their simple transitive complementation believe, judge and consider (unlike imagine, picture or expect) are extensional. One cannot truly believe a unicorn, because there are no such things. Likewise, if one believes Boris Karloff (is telling the truth) one believes Bill Pratt because they are one and the same individual, and so on.

It is an interesting question as to why predicate in the implicit ECM complement must be stage-level, and hence why there are no intensional transitive believe, judge or consider selecting $\mathrm{X}_{\text {INDIVIDUAL-LEVEL }}$. One possible approach is suggested by the work of Diesing $(1990,1992)$, who proposes (in essence) that stage-level predicates involve raising whereas individual-level predicates require control. On Diesing's account, stage-level predicates $\theta$-mark the overt subject DP internal to their maximal projections (87a); this subject may subsequently raise. By contrast, individual-level predicates $\theta$-marks a null subject internal to their projection (identified as $P R O$ by Diesing). The overt subject DP is $\theta$-marked externally, and the relation between DP and $P R O$ is basically one of control (87b).

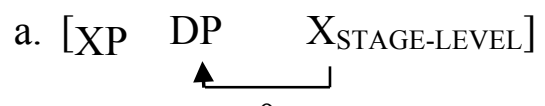

$\theta$

\footnotetext{
${ }^{39}$ In judging (85a-c), one must be careful to avoid the interpretation of available as 'eligible' or 'marriageable'. One must also avoid the construal of on the boat as an adverb.
} 


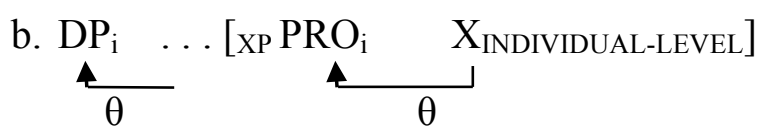

The crucial difference, for our purposes, is that the individual-level predicates require a projection higher than XP to contain their overt subject and assign it a $\theta$-role, whereas the stagelevel predicates don't. Suppose then that in ECM intensional transitives, the verb selects a lexical predicate directly (AP or PP), with no surrounding functional shell:

$[\mathrm{VP}$ imagined $[\mathrm{XP} \quad \mathrm{DP} \quad \mathrm{X}]$

Then there simply will be "no room" for the predication relations required of an individual-level predicate. The latter will be excluded because the complements to ECM intensional transitives are not just small clauses, but very small clauses. ${ }^{40}$

\subsection{The Case of Expect}

The availability of two different structures for intensional transitives has interesting implications for verbs which can participate in both. Consider the verb expect. As is well-known, infinitival constructions like (89a) appear to be ambiguous between a want-type analysis and a believe-type analysis. Familiar evidence for the first analysis is the appearance of expect with overt for complements (89b); evidence for the latter is the availability of passive (89c):
a. John expects [Mary to win]
b. What John expects is [for Mary to win]
(want-type)
c. Mary is expected [ $t$ to win]
(believe-type)

Consider now an intensional transitive construction like (90). DeCarrico (1983) observes that examples like this with expect can be understood in two quite different ways. On the one hand, Max can be understood as expecting to receive an airplane, for example, as a gift for Christmas (90a); on the other hand, Max can be expecting an airplane to appear or arrive, for example, at the airport, or at his door (90b):

(90) Max is expecting an airplane.

a. 'Max is expecting to get/have an airplane'

b. 'Max is expecting an airplane to arrive'
(DeCarrico (1983))

(e.g., for Christmas)

(e.g., at the airport)

Under an analysis that takes the complement of expect in (90) to be a bare nominal (DP), this variation must apparently be viewed as reflecting simple vagueness in the ways in which one can expect something. Interestingly, however, the polysemy seen here does not behave like vagueness, but rather like genuine ambiguity. Consider the conjunction in (91), setting up the

40The deduction that imagine-type verbs take stage-level SC complements actually requires an additional, but independently plausible adaptation of Li's (1991) theory of head movement restrictions in terms of the binding theory. If, as we suppose, the lexical head of the predicate of imagine's SC complement incorporates into $\mathrm{V}$, then there can be no functional shell between this L-head and V, since L-to-F-to-L (L=lexical, F=functional) head movement is blocked. So the fact that only (88) is available follows. 
standard parallelism test for vagueness versus ambiguity (Zwicky and Saddock 1975). It appears to us quite clear that, except as a joke, it is not possible to "cross" the readings of the implicit complements of expect. Thus Max and Fred can both be understood as expecting to get an airplane, or both as expecting an airplane to arrive or appear. But we cannot understand their expectations differently:

(91) Max is expecting an airplane, and Fred is too.

a. i. Max is expecting to get/have an airplane, and Fred is expecting to get/have an airplane too.

ii. Max is expecting an airplane to arrive, and Fred is expecting an airplane to arrive too.

b. i. \# Max is expecting to get/have an airplane, and Fred is expecting an airplane to arrive.

ii. \# Max is expecting an airplane to arrive, and Fred is expecting to get/have an airplane.

Under the idea that expect takes a simple nominal, this outcome is quite surprising. By contrast, this result is straightforward under our account, which assigns the two fundamentally different structural representations to (91), namely (92a) and (92b):
a. Max [vp expected [cP [C, FOR [AgrsP PRO TO [vp HAVE an airplane]]]]

b. Max [vP expected [XP an airplane $\left.\left.\mathrm{X}_{\mathrm{STAGE}-L E V E L}\right]\right]$

\section{Extensions and Further Questions}

Thus far we have shown the plausibility of a covert clause analysis for certain core cases of intensional transitive verbs. Quite apart from the intrinsic interest of this project, these results appear to lend support to the broader hypothesis that intensionality effects may be universally correlated with clausal complementation. This in turn raises certain interesting conceptual issues about the foundations of semantic theory. Specifically, are so-called sententialist theories of intensional environments adequate, or do we also need to invoke the resources of abstract intensional objects and possible worlds semantics? ${ }^{41}$ Partee (1974) puts the issue in the following way:

"As far as I know, there aren't more than one or two dozen verbs like look for; I have only been able to find look for, search for, seek, hunt for, hunt, ransack...for, rummage about for, advertise for, listen for, guard against, and owe. If these verbs were missing from the language, or if their syntax were slightly different, then there would seem to be no empirical difference between the theory that all opacity results from sentenceembedding and the theory that intensions are centrally involved in the semantic interpretation of all or most grammatical relations. Since these two hypotheses are linked with very different views about the degree of abstractness needed in syntax for natural languages, basic questions about the relation between syntax and semantics in natural

\footnotetext{
${ }^{41}$ See the introduction to section 6 of Ludlow (1997) for a general discussion of these two approaches to intensionality.
} 
language are at issue. Although I believe I have shown that the balance of the available evidence goes against the hypothesis that all opaque contexts are sentential contexts and in favor of basic grammatical relations being intensional, it is certainly to be hoped that clearer kinds of evidence on the question will eventually be discovered. " (p.100)

What we have shown thus far seems to suggest that, contrary to Partee's assumptions, a sentence-embedding account of opacity is possible - indeed correct - in all of the cases that she mentions. But the question remains: Can all cases of opacity be assimilated to cases of clausal complementation? In this final section we examine a number of additional cases that appear to be obstacles to such assimilation, and we offer some speculative remarks on how these obstacles might be overcome.

\subsection{Two More Classes of Intensional Transitive Verbs}

Psychological predicates like fear, worry-about, love, despises, frighten, irritate, please, etc. (93)-(94) present interesting questions for the account given here: ${ }^{42}$

a. Max fears Boris Karloff/Bill Pratt.

b. Alice likes unicorns.

a. Boris Karloff/Bill Pratt frightens Max.

b. Unicorns please Alice.

Kaplan (1986) has observed that even though psychological predicates typically permit a clausal complement, it is not clear that cases in which the predicate is followed by a bare NP need be equivalent to cases with a propositional complement. Consider (95a), for instance. While this sentence might be understood as an abbreviation of what is expressed more fully by the propositional constructions in (95b), it also seems possible to think of Max, described by (95a), as simply sharking-fearing. It's not that he has any particular fear about what sharks will try to

\footnotetext{
${ }^{42}$ Some researchers have questioned the status of psychological verbs as intensional. Thus Forbes (1997b) expresses doubts similar to those of Zimmermann (1995) about the availability of narrow scope readings (what Forbes refers to as "notional readings") with examples like (i):

(i) Perseus fears a gorgon.

The situation here seems to us analogous to the case of seek discussed in section 3.2.2; that is., although de re readings are generally (and often strongly) preferred in the surface transitive construction, de dicto (in Forbes' terms "relational") readings are nonetheless possible. Consider (ii) for instance:

(ii) Max feared/worried-about typos in his manuscript.

It seems plain to us that (ii) can report a general fear or worry on Max's part that could be expressed as follows: "Max fears that typos exist in his manuscript". The latter is not reducible to a de re reading of the object, nor is it a generic reading. Consider also the more complex (iii):

(iii) Max fears [mistakes in any manuscript by a foreign author].

Notice that not only can the bracketed object be read de dicto, but that on that reading the scope relations between any manuscript and mistakes are naturally read as inverted. Thus (iii) is understood as:

(iv) Max fears [in any $\mathrm{x}$ : ms-by a foreign author (x)] [for some y: typo (y) \& in (x,y) ] exist (y)

Unless logical resources are enhanced to permit quantifying into NP (see Larson 1985), a hidden clausal analysis seems inescapable in this context. It is also worth observing, following den Dikken, Larson and Ludlow (1996), that verbs like fears do admit an adverb attachment ambiguity, as in (v).
}

(v) Max feared a storm tomorrow (after he heard the weather report) 
do to him; he's just afraid of sharks.

a. Max fears sharks

b. Max fears that sharks will maim/bite/devour/kill him.

(Max fears to have a shark maim/bite/devour/kill him)

Our view of this class of cases follows that proposed in den Dikken, Larson and Ludlow (1996). Namely, we believe that fear (and similar predicates) are simply ambiguous between two different senses. One is propositional/attitudinal: the subject fears that so and so. The second sense is non-propositional and non-attitudinal: the subject has a phobia about X. To understand the difference consider the situation of Max swimming in the ocean versus Max visiting a local aquarium; in both cases he sights the familiar curved fin of a shark. There is a natural understanding of (95a) such that it is true in the first circumstance but not in the second. This is the propositional understanding. In the first situation, Max has a fear of what sharks might do to him, for example, one of the fears expressed in (95b). In the aquarium, however, he has no such fears; the sharks are safely behind a glass wall, etc.

There is also a second understanding of (95b), under which sharks are the occasion for an emotional reaction of fear in Max whenever he is in their presence, whatever the circumstances. On this second understanding, (95a) might be true in both the situations given above. Whether in the ocean or within a glass tank, sharks make Max fearful. Notice that in precisely this case we would be inclined to talk about Max having a shark-phobia. Interestingly, complements of phobia appear to be transparent in the usual sense. Thus consider a phobia on Max's part to hazelnuts. It seems to us that if (96a) is true, then (96b) must be true as well, given the coextension of hazelnut and filbert; similarly for $(97 \mathrm{a}, \mathrm{b})$ :

(96) a. Max has a phobia about hazelnuts.

b. Max has a phobia about filberts.

(97) a. Max has a phobia about Boris Karloff.

b. Max has a phobia about William Henry Pratt.

The issue of nondenoting terms is a bit less clear however. While it is obvious that a child can fear gremlins or hobgoblins, in the sense of fearing that they might be hiding under their bed or in a closet, it is much less clear that one can have a gremlin or goblin phobia. It is not clear how goblins can be the occasion of fear on the part of an individual when no such creatures exist. On the basis of these considerations, the prospects for an example like (98) being true seem to us at best very unclear:

Max has a phobia about goblins.

Thus, although we will not attempt to pursue the issue further, it appears to us that, when divided properly into their propositional and nonpropositional senses, a concealed clause analysis of emotion verbs like fear, like, frighten and please is available in principle. ${ }^{43}$

\footnotetext{
${ }^{43}$ Psychological predicates such as frighten and irritate show intensionality effects in their subject position. This result appears to support the general proposal by Belletti and Rizzi (1988) that the subjects of "psych" verbs of this
} 
A rather different challenge is presented by verbs of veneration, including, worship, revere, venerate, adore, etc. (99):

a. Sophocles worshipped Zeus.

b. Native Australians venerate the Great Rock Python.

While these examples have some of the marks of intensionality (one can judge $(99 a, b)$ to be true without believing in Olympian gods or figures of Australian dreaming), Montague (among others) took these to be abberant cases. The puzzle presented by these verbs is that while one can truthfully be said to worship nonexistent objects like Zeus, it is not so obvious that substitution fails in these contexts. For example, if one worships Zeus is one not thereby worshiping Jupiter? (One is reminded of the Apostle Paul preaching at the temple of the unknown god, arguing that they had been worshiping his God all along.) Our intuitions on these cases are far from clear.

Despite these doubts, however, we do not mean to close the door on further investigation of this class of verbs, and indeed, there are a number of possible lines of inquiry which might be pursued if it could be established that these verbs are genuinely intensional. One possibility is to argue that a proper understanding of this class of verbs requires a better grasp on the covert predicate. Predicates like be and small clause predicates appear inadequate, as the examples in (100a-c) show; but there are other possibilities, such as (100d), where the apparent object NP occurs within a purpose clause:

(100) a. *Sophocles worshiped [that Zeus be]

b. *Sophocles worshiped [for Zeus to be]

c. *Sophocles worshiped [Zeus on his throne]

d. Sophocles worshiped [PRO to please/glorify Zeus]

Reasoning might then proceed basically as in the cases of seek and look for. ${ }^{44}$

\subsection{Pseudo-Intensionals}

Comparative constructions, in the broad sense of constructions that express comparisons between properties, have sometimes been taken in the literature as being intensional. ${ }^{45}$ This view is based upon apparent possibility of truthfully compare non-existents, or existents and non-existents:

class are moved to the subject position from a within the VP. On our approach the latter must be located within some form of clausal complement:

(i) $\quad[$ Sharks $]$ are $[\mathrm{VP}$ frightening Bill $[$...t ...] ]

We will not attempt to spell out the details of this analysis further at this point.

${ }^{44}$ Interesting facts from Dutch suggest other avenues of analysis as well. Note that the Dutch verbs of worship and veneration are morphologically complex:

(i) ver-eren "worship"

VER-honour

(ii) aan-bidden "adore/worship"

PRT-pray

These suggest that the inability of worship to take overt (small) clausal complements, as in (100a-c), in fact might be due to the fact "worship" always takes a small clausal complement with an abstract predicate.

${ }^{45}$ See, for example, Zimmermann (1993). 
(101) a. Hercule Poirot was as smart as Sherlock Holmes.

b. Paul Bunion was stronger than any living man.

(102) a. Hercule Poirot equaled Sherlock Holmes in intelligence.

b. Paul Bunyan exceeded any living man in strength.

(103) a. Max is similar to Sherlock Holmes.

b. Max resembles Sherlock Holmes.

If these constructions are indeed intensional in the usual sense, then they present a clear challenge for us. No suitable clausal complement paradigms seem appropriate for (101)-(103). ${ }^{46}$

In fact we believe that the possibility of truth in comparatives containing non-denoting terms arises from a very different source than in intensional transitives like those discussed above. To make clear the difference, let us consider a simple "Twin Earth" style thought experiment involving Max and twin-Max. Max and twin-Max, although non-identical, are assumed to be alike in all relevant respects; they are physically identical down to the finest details of atomic composition; they have counterpart personal histories; they live their lives in identical circumstances in their respective worlds. If Max is the son of Minnie on Earth, then twin-Max is the son of twin-Minnie on Twin Earth, etc. With this background in mind, consider the three pairs in (104):

(104) a. Seymour pinched/saw/greeted Max Seymour pinched/saw/greeted twin-Max

b. Seymour needs/seeks/imagines Max Seymour needs/seeks/imagines twin-Max

c. Seymour resembles/is similar to/ is smarter than Max

Seymour resembles/is similar to/ is smarter than twin-Max

Substitution of twin-Max for Max plainly fails to preserve truth in normal transitives: obviously Seymour can pinch Max without thereby pinching his Twin-Earth counterpart. Likewise, substitution of twin-Max for Max clearly fails to preserve truth in intensional transitives: Seymour can surely seek Max without thereby seeking his Twin-Earth counterpart (indeed, Seymour may have no idea that Max even has a dopplegänger). However, substitution of twinMax for Max does preserve truth in comparative constructions. By assumption, Max and twinMax are identical in all non-relational properties. Accordingly, if Seymour resembles/is similar to Max, he will resemble/ be similar to twin-Max. Likewise, for any adjective A (tall, deceptive, handsome, poor, etc.), the following with be true:

(105) a. Seymour is as A as Max $\Leftrightarrow$ Seymour is as A as twin-Max

b. Seymour is more A than Max $\Leftrightarrow$ Seymour is more A than twin-Max

c. Seymour is less A than Max $\Leftrightarrow$ Seymour is less A than twin-Max

\footnotetext{
${ }^{46}$ Barry Schein (p.c.) notes that resemble/similar take small clause predicates (ia) and might be viewed as raising verbs similar to appear and seem (ib):

(i) a. John resembles Max in his prime.

b. $\mathrm{John}_{\mathrm{i}}$ resembles [ $\mathrm{t}_{\mathrm{i}}$ Max in his prime].

The suggestion is intriguing one but we will not attempt to pursue it here.
} 
What this shows, we believe, is the following: both intensional transitives and normal transitives have a semantics that "sorts" their postverbal NPs at least as finely as reference to objects. Accordingly, with both intensional transitives and normal transitive verbs, truth-conditions are sensitive to substitution of terms that refer to different individuals. By contrast, the truth conditions of a comparative appear to be more coarse-grained than reference to objects. Substitution of a non-co-referring term will preserve truth so long as the relevant properties are the same.

If this line of reasoning is correct (and the contrast between (104a-c) suggests that it is), then it indicates a very different diagnosis of the possibility of truth with non-denoting "objects" in intensional transitives versus comparatives. Intensional transitives allow truth with nondenoting terms because they involve standing in relation to something finer grained than referents. On a Fregean account, terms in a propositional complement refer to their senses, and not their normal referents. By contrast, comparative constructions allow truth with nondenoting terms because they involve standing in relation to something more coarse-grained than referents. What appears to true with comparatives is that terms contribute sets of properties. The effect is like that of intensionality: just as one can stand in relation to a sense even if there is no referent, one can (apparently) stand in relation to set of properties even if there is no thing that they are the properties of. Nonetheless, the difference between relation to senses and relation to properties becomes clear with substitution (104a-c). Intensionality is at least as sensitive to reference as a transitive verb, whereas comparatives are not. ${ }^{47}$

We will not attempt to propose a semantics for comparison, satisfying ourselves with the fact that comparatives involve a fundamentally different phenomenon than the intensional transitivity examined here. We think it correct to regard comparatives as presenting at most a form of "pseudo-intensionality", with examples like (101)-(103) presenting no threat to the line of analysis advanced here.

\subsection{Intensional Transitive Predicates of Other Categories}

Our sententialist approach to intensionality entails the existence of hidden complements of other categories of predicates, in addition to verbs. Consider the nominal complements in (106)-(108), and the adjectival complements in (109): ${ }^{48}$

\footnotetext{
${ }^{47}$ Further evidence that comparatives are concerned with properties rather than the referents of NPs comes from the fact that many of our apparently true attributions would be flat out false if we were talking about the referent rather than the properties that the referent (or representation of the referent) is purported to have. So, for example, if we point to a well-fed bearded man in a red jumpsuit and say He resembles Santa Claus we are not talking about the historical figure (who was no doubt thin and wore earth-tones), but rather the gaudy commercial representations of Santa. Likewise, here is a real life discourse overheard by one of the authors (PL):

A: He looks like Jesus.

B: Oh yeah, how do you know what Jesus looked like?

A: *Pictures* of Jesus, you dolt!

Clearly there is an implicit understanding that in this and related cases, when we are talking about resembling X, we are talking about resembling some canonical representation of $\mathrm{X}$, not $\mathrm{X}$ itself.

${ }^{48} \mathrm{We}$ find it striking that most of these non-verbal intensional transitives are deverbal (or, to put it more neutrally, have a verbal counterpart which is morphologically related). This raises the question of whether the presence of $\operatorname{Agr}_{0} \mathrm{P}$ in the extended projection of $\mathrm{N}$ (and A) restricted to those Ns (and As) which have a morphological link with corresponding verbs. Perhaps most (if not all) of these cases as basically verbal, turning into a nominal in the course of the syntactic derivation (i.e., as a result of building a nominal projection on top of a verbal extended projection.)
} 
(106) a. Polly's hopes for a Ritz-cracker (were dashed). (cf. Polly's hope to have a Ritz-cracker.)

b. Max's desire for a unicorn (is fruitless). (cf. Max's desire to have a unicorn.)

c. Her preference for artichokes (is well-known). (cf. Her preference to have artichokes.)

(107) a. Max conducted every search for a boy with red hair. (cf. Every search to find a boy with red hair.)

b. Max's search of the premises for the missing items

(108) a. Polly's image of a Ritz-cracker (was elaborate). (cf. Polly imagined a Ritz-cracker on her feeding tray.)

b. A picture of a unicorn was on the computer screen (cf. A picture of a unicorn standing in a field was on the computer screen) c. Our image/picture of John as intelligent.

(109) a. ?Max is desirous for Aphrodite.

b. Max is hungry for a cracker.

c. Polly is thirsty for a margarita.

All of these constructions exhibit the familiar earmarks of intensionality. Plainly, Max can have the desire for a unicorn, even if there are no unicorns; likewise, he could have a preference for Boris Karloff (say, to act in a film) without thereby having a preference for Bill Pratt. There can be searches for unicorns, even if there are no unicorns; and there can be searches for Boris Karloff that are not searches for Bill Pratt. Finally, Max can (it seems) be desirous for Aphrodite, even though the Greek goddess of love does not exist. And he could have been desirous for Lauren Bacall without being desirous for Betty Joan Perske, even though they were one and the same glamorous movie actress. And so on.

Our analysis implies that clausal complementation is present in all of these cases. For example, (106a) presumably gets an analysis as in (110), where $\operatorname{Agr}_{0}, P R O, H A V E$, etc. occur just as in the verbal cases: 
(110)

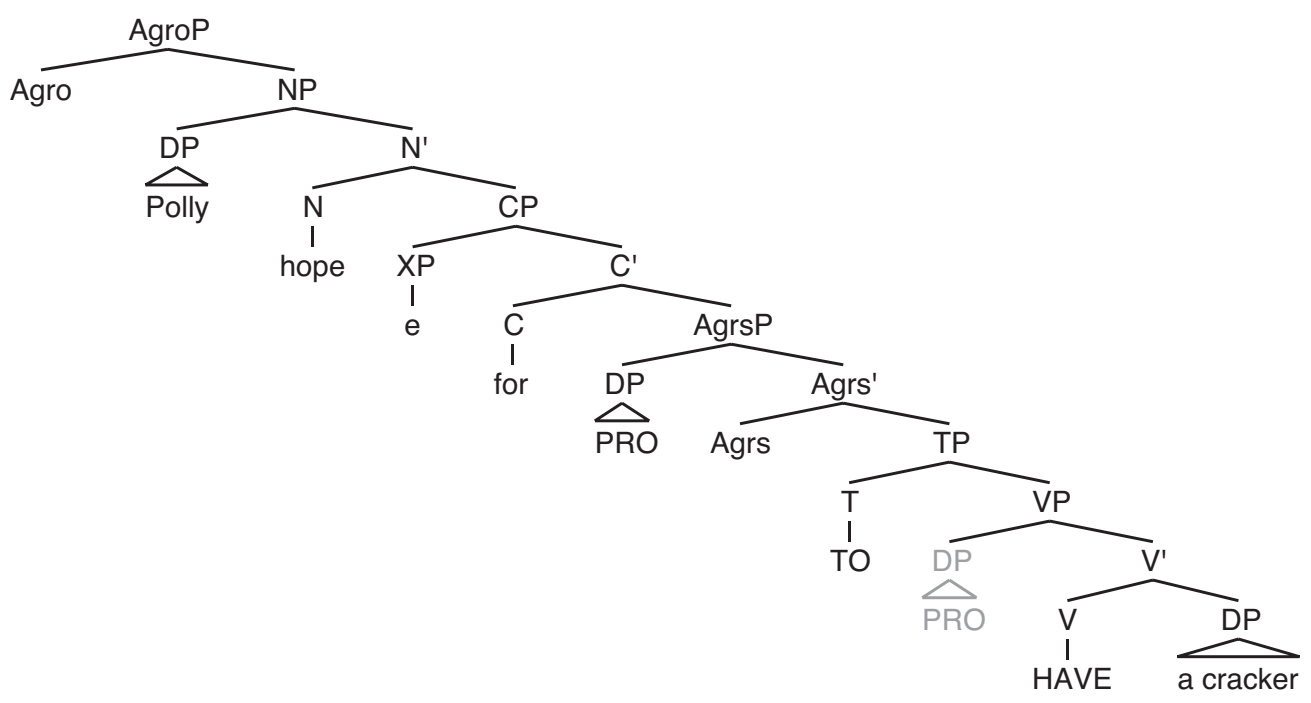

The latter presumably undergoes restructuring, incorporation of for, and subsequent raising of the infinitival subject to Spec Agro, just as in the case of the verb hope. Similarly, in the case of search we presumably have a hidden clausal complement containing a covert verb FIND, with subsequent raising and restructuring, etc.

Furthermore, the range of syntactic-semantic complexity observed in the verbal cases must also apparently be attributed to other categories. Recall our earlier examples with the verb search. We noted that the object nominal in (111a) was extensional, whereas the nominal complement to for in (111b) was intensional; the extensional and intensional complements could moreover be combined, as in (111c):

(111) a. Max searched the forest.

b. Max searched for a unicorn.

c. Max searched the forest for a unicorn.

The same facts obtain with the noun search, as shown by (112). The object of of in (112a) is extensional, whereas the nominal complement of for in (112b) is intensional; these extensional and intensional complements can again be combined, as shown in (112c).

(112) a. A search of the premises (was unsuccessful).

b. A search for the missing items (was unsuccessful).

c. A search of the premises for the missing items (was unsuccessful).

With the verb search we postulated both an object and a concealed infinitive containing FIND. The extensional object arises in the matrix clause and the intensional NP arises within a concealed complement clause as the object of FIND (113a). At Logical Form, both the forest and a unicorn raise to Spec of $\mathrm{Agr}_{\mathrm{o}}$ where their Cases are checked by the separate contributions of the searched-FIND-for complex (113b):

(113) a. searched [the forest] [CP for [AgrsP ... [FIND a unicorn]]]

b. [the forest] [a unicorn] [Agrop searched-FIND-for $t \quad[\mathrm{CP} \ldots[$ AgrsP $\ldots . . t]]]$ 
Presumably a highly parallel derivation occurs with (112c). The extensional object arises in the matrix clause and the intensional NP within the concealed complement clause (114a). At Logical Form, the preposition of and the complementizer for incorporate into the noun along with the verb FIND. Both the forest and a unicorn raise to Spec of $\mathrm{Agr}_{\mathrm{o}}$ in the nominal where their Cases are checked by the search-FIND-of-for complex (114):

(114) a. search [of [the forest] $]$ [CP for [AgrsP ... [FIND a unicorn]]]

b. [the forest] [a unicorn] [AgroP search-FIND-of-for [ $\mathrm{t}][\mathrm{CP} \ldots[$ AgrsP ... $\mathrm{t}]]]$

The attribution of full agreement structure and Case-checking across categories evidently has a wide variety of implications, which we cannot pursue here. ${ }^{49}$

Again, our goal in this section has not been to nail down the connection between clausal complementation and intensionality, but rather to offer some suggestive lines of investigation for the remaining few constructions that appear to be counterexamples. Working out a full analysis of any of these constructions will doubtless require some deeper understanding of abstract clausal complementation, just the analysis of seek and look for cases did.

Overall, our principle goal has been to secure the clausal analysis of the core intensional transitive verbs (including cases like seek). The payoff, in our view, is not merely a firmer grasp on the nature of intensionality, but (just as importantly) a better understanding of phenomena ranging from case assignment to restructuring. More generally, however, we believe that by opening up an "invisible" domain like abstract clausal complementation, a number of interesting new questions and lines of investigation will emerge, and hopefully they will in turn interact with current theory in interesting and fruitful ways.

\section{References}

Aissen, Judith and David Perlmutter. 1983. "Clause Reduction in Spanish." In D. Perlmutter (ed.), Studies in Relational Grammar 1, Chicago: University of Chicago Press, pp. 360403.

Bach, Emmon. 1977. "Review Article on On Raising: One Rule of English Grammar and its Theoretical Implications". Language 53, 621-654.

Baker, Mark. 1988. Incorporation. A Theory of Grammatical Function Changing. Chicago: University of Chicago Press.

Bhandari, Rita. 1996. Scrambling and Chain-formation in Hindi. Unpublished ms. State University of New York at Stony Brook.

Bonomi, Andrea. 1995. "Transparency and Specificity in Intensional Contexts." In P. Leonardi and M. Santambrogio (eds.), On Quine: New Essays. Cambridge: Cambridge University Press, pp. 164-185.

Borkin, Ann. 1984. Problems in Form and Function. Norwood: Ablex.

\footnotetext{
49 This result converges with recent work by Bhandari (1996) which suggests on grounds arising from the analysis of subject-orientation in anaphora that nominals must also possess functional category structure parallel to sentences, including TP and AgrP.
} 
Boskovic, Zeljko. 1995. Principles of Economy in Nonfinite Complementation. Ph.D. Dissertation, University of Connecticut, Storrs, CT.

Bresnan, Joan. 1972. Theory of Complementation in English Syntax. Ph.D. Dissertation, MIT, Cambridge, MA.

Buridan, John. 1966. Sophisms on Meaning and Truth. Trans. T. K. Scott. New York: AppletonCentury-Crofts.

Burzio, Luigi. 1986. Italian Syntax. Dordrecht: D. Reidel Publishing Co.

Carlson, Greg. 1977. Reference to Kinds in English. Ph.D. Dissertation, University of Massachusetts-Amherst, Amherst, MA.

Cho, Sungeun. 1997. "Inalienable Possession and Multiple Accusative Marking in Korean." unpublished ms. State University of New York at Stony Brook.

Chomsky, Noam. 1981. Lectures on Government and Binding. Dordrecht: Foris.

Chomsky, Noam. 1995. The Minimalist Program. Cambridge: MIT Press.

DeCarrico, Jeanette. 1983. "On Quantifier Raising," Linguistic Inquiry 14, 343-346.

Den Dikken, Marcel, Richard Larson and Peter Ludlow 1996. "Intensional 'Transitive' Verbs and Concealed Complement Clauses," Rivisita di Linguistica 8, 29-46.

Diesing, Molly. 1990. The Syntactic Roots of Semantic Partition. Ph.D. Dissertation, University of Massachusetts-Amherst, Amherst, MA.

Diesing, Molly. 1992. Indefinites. Cambridge: MIT Press.

Fiengo, Robert and Robert May 1993. Indices and Identity. Cambridge: MIT Press.

Forbes, Graeme. 1996. "Substitutivity and the Coherence of Quantifying-in." The Philosophical Review 105.

Forbes, Graeme. 1997a. "How Much Substitutivity?" Analysis 57, 109-113.

Forbes, Graeme. 1997b. Objectual Attitudes. Unpublished ms. Tulane University.

Hornstein, Nobert. 1994. "An Argument for Minimalism: The Case of Antecedent Contained Deletion," Linguistic Inquiry 25, 455-480.

Hornstein, Nobert. 1995. Logical Form: From GB to Minimalism. New York: Basil Blackwell.

Iatridou, Sabine. 1993. "On Nominative Case Assignment and a Few Related Things." In C. Phillips (ed.), Papers on Case \& Agreement II. MIT Working Papers in Linguistics Volume 19. Cambridge: MITWPL.

Kaplan, David. 1986. "Opacity." In L. Hahn and P. Schilpp (eds.), The Philosophy of W.V. Quine. LaSalle: Open Court.

Karttunen, Lauri. 1976. "Discourse Referents." In J. McCawley (ed.), Syntax and Semantics 7: Notes From the Linguistic Underground. New York: Academic Press, pp. 363-385.

Kayne, Richard. 1983. "On Certain Differences Between French and English." In R. Kayne (ed.), Connectedness and Binary Branching. Dordrecht: Foris, pp. 103-123.

Kennedy, Christopher. 1997. "Antecedent Contained Deletion and the Syntax of Quantification", Linguistic Inquiry 28: 662-688.

Klima, Edward. 1964. "Negation in English." In J. Fodor and J. Katz (eds.), The Structure of Language, Englewood Cliffs, NJ: Prentice-Hall, pp. 246-323.

Ladusaw, William. 1992. "Expressing Negation." In C. Barker and D. Dowty (eds.), Proceedings of the Second Conference on Semantics and Linguistics Theory. Columbus: Ohio State University Dept. of Linguistics, pp. 237-259.

Larson, Richard. 1985. "Quantifying Into NP." unpublished ms., MIT.

Larson, Richard and Robert May. 1990. "Antecedent Containment or Vacuous Movement: Reply to Baltin," Linguistic Inquiry 21:103-122. 
Lasnik, Howard. 1993. "Lectures on Minimalist Syntax," UCONN Working Papers in Linguistics. Occasional Papers Issue 1. Cambridge: MITWPL.

Lasnik, Howard and Mamoru Saito. 1991. "On the Subject of Infinitives," in L. Dobrin, L. Nichols and R. Roderiguez (eds.), Papers From the 27th Regional Meeting of the Chicago Linguistics Society. pp. 324-343) Chicago: University of Chicago.

Ludlow, Peter. 1985. The Syntax and Semantics of Referential Attitude Reports. Ph.D. Dissertation, Columbia University, New York, NY.

Ludlow, Peter. 1997. Readings in the Philosophy of Language. MIT Press, Cambridge.

Martin, Roger. 1992. On the Distribution and Case Features of PRO. Unpublished ms. University of Connecticut.

May, Robert. 1985. Logical Form: Its Structure and Derivation. MIT Press, Cambridge.

McCawley, James. 1974. "On Identifying the Remains of Deceased Clauses." In J. McCawley, 1979, pp. 74-85.

McCawley, James. 1979. Adverbs, Vowels, and Other Objects of Wonder. Chicago: University of Chicago Press.

Montague, Richard. 1974. Formal Philosophy. New Haven: Yale University Press.

Montague, Richard. 1960. "On the Nature of Certain Philosophical Entities." In Montague 1974.

Moltmann, Friederike. 1997. "Intensional Verbs and Quantifiers." Natural Language Semantics $5,1-52$.

Ormazabal, Javier. 1995. The Syntax of Complementation: On the Connection Between Syntactic Structure and Selection. Ph.D. Dissertation, University of Connecticut, Storrs, CT.

Parsons, Terence. 1997. "Meaning Sensitivity and Grammatical Structure." In M.L. Dalla Chiara et al. (eds.), Structures and Norms in Science. Dordrecht: Kluwer, pp. 369-383.

Partee, Barbara. 1974. "Opacity and Scope." In M. Munitz and P. Unger (eds.), Semantics and Philosophy. New York: New York University Press, pp. 81-101.

Pesetsky, David. 1995. Zero Syntax: Experiencers and Cascades. Cambridge: MIT Press.

Postal, Paul. 1974. On Raising: One Rule of English Grammar and its Theoretical Implications. Cambridge: MIT Press.

Quine, Willard V.O. 1960. Word and Object. Cambridge: MIT Press.

Reinhart, Tanya. and Eric Reuland 1993. "Reflexivity." Linguistic Inquiry 24, 657-720.

Rizzi, Luigi. 1978. "A Restructuring Rule in Italian Syntax." In S.J. Keyser (ed.), Recent Transformational Studies in European Languages. Cambridge: MIT Press.

Roberts, Ian. 1997. "Restructuring, Head-Movement and Locality". Linguistic Inquiry 28, 423460.

Rooth, Mats. 1985. Association with Focus. Ph.D. Dissertation, University of MassachusettsAmherst, Amherst, Massachusetts.

Ross, John. 1976. "To Have Have and to Not Have Have." In M. Jazayery, E. Polom, and W. Winter (eds.), Linguistic and Literary Studies in Honor of Archibald Hill. Lisse, Holland: de Ridder, pp. 263-270.

Sigurdsson, Halldor. 1991. "Icelandic Case-marked PRO and the Licensing of Lexical Arguments." Natural Language and Linguistic Theory 9, 327-363.

Stowell, Tim. 1982. "The Tense of Infinitives," Linguistic Inquiry 13, 561-570

Terzi, Arhonto. 1992. PRO in Finite Clauses: A Study of Inflectional Heads in the Balkan Languages. Ph.D. Dissertation, City University of New York, New York, NY. 
Watanabe, Akira. 1993. "The Notion of Finite Clauses." In J. Bobaljik and C. Phillips (eds.), Papers on Case \& Agreement I. MIT Working Papers in Linguistics Volume 18. Cambridge: MITWPL.

Wurmbrand, Susi. 1996. Restructuring Infinitives. Unpublished ms., MIT.

Zimmermann, Thomas. 1993. "On the Proper Treatment of Opacity in Certain Verbs," Natural Language Semantics 1, 149-179.

Zwicky, Arnold and Jerrold Saddock. 1975. "Ambiguity Tests and How to Fail Them." In J. Kimball (ed.), Syntax and Semantics 4. New York: Academic Press, pp. 1-36.

\author{
Richard Larson \\ Department of Linguistics \\ Stony Brook University \\ Stony Brook, NY 11794-4376 \\ USA \\ Richard.larson@stonybrook.edu \\ Marcel den Dikken \\ Department of Linguistics \\ The City University of New York Graduate Center \\ 365 Fifth Avenue \\ New York, NY 10016-4309 \\ USA \\ MDen-Dikken@gc.cuny.edu \\ Peter Ludlow \\ Department of Philosophy \\ Northwestern University \\ 1860 Campus Drive \\ Evanston, IL 60208 \\ USA \\ peterjludlow@gmail.com
}

